\title{
Influence of the amino-terminal sequence on the structure and function of HIV integrase
}

\author{
Grant Eilers ${ }^{1}$ [0, Kushol Gupta ${ }^{2}$, Audrey Allen ${ }^{1,2}$, Jeffrey Zhou ${ }^{1,2}$, Young Hwang ${ }^{1}$, Michael B. Cory², \\ Frederic D. Bushman ${ }^{1 *}$ and Gregory Van Duyne $2^{2^{*}}$
}

\begin{abstract}
Background: Antiretroviral therapy (ART) can mitigate the morbidity and mortality caused by the human immunodeficiency virus (HIV). Successful development of ART can be accelerated by accurate structural and biochemical data on targets and their responses to inhibitors. One important ART target, HIV integrase (IN), has historically been studied in vitro in a modified form adapted to bacterial overexpression, with a methionine or a longer fusion protein sequence at the $\mathrm{N}$-terminus. In contrast, IN present in viral particles is produced by proteolytic cleavage of the Pol polyprotein, which leaves a phenylalanine at the N-terminus (IN 1F). Inspection of available structures suggested that added residues on the $\mathrm{N}$-terminus might disrupt proper protein folding and formation of multimeric complexes.

Results: We purified HIV-1 IN $1 \mathrm{~F}^{1-212}$ and solved its structure at $2.4 \AA$ resolution, which showed extension of an $\mathrm{N}$-terminal helix compared to the published structure of $\mathrm{IN}^{1-212}$. Full-length IN $1 \mathrm{~F}$ showed increased in vitro catalytic activity in assays of coupled joining of the two viral DNA ends compared to two IN variants containing additional $\mathrm{N}$-terminal residues. IN $1 \mathrm{~F}$ was also altered in its sensitivity to inhibitors, showing decreased sensitivity to the strandtransfer inhibitor raltegravir and increased sensitivity to allosteric integrase inhibitors. In solution, IN $1 \mathrm{~F}$ exists as monomers and dimers, in contrast to other IN preparations which exist as higher-order oligomers.
\end{abstract}

Conclusions: The structural, biochemical, and biophysical characterization of IN $1 \mathrm{~F}$ reveals the conformation of the native HIV-1 IN N-terminus and accompanying unique biochemical and biophysical properties. IN $1 \mathrm{~F}$ thus represents an improved reagent for use in integration reactions in vitro and the development of antiretroviral agents.

Keywords: Integrases, Retroviridae, HIV, X-ray crystallography, Protein structure, Biophysics

\section{Background}

Integration of a reverse-transcribed DNA copy of the HIV RNA genome into a host cell chromosome is an essential step in retroviral replication [1]. The integrated provirus serves as a template for retroviral gene expression and the production of a new generation of virions. Integration also establishes the potential for latency, a major barrier to the treatment and cure of

\footnotetext{
*Correspondence: bushman@pennmedicine.upenn.edu; vanduyne@pennmedicine.upenn.edu

${ }^{1}$ Department of Microbiology, Perelman School of Medicine, University of Pennsylvania, Philadelphia, PA, USA

${ }^{2}$ Department of Biochemistry and Biophysics, Perelman School

of Medicine, University of Pennsylvania, Philadelphia, PA, USA
}

HIV-1 infection. Integrase (IN), the retroviral enzyme that catalyzes integration, is produced by proteolysis of the viral Gag-Pol polyprotein precursor by the virusencoded protease. HIV-1 IN is comprised of three domains: the $\mathrm{N}$-terminal (NTD), catalytic core (CCD), and $\mathrm{C}$-terminal (CTD) domains. Some non-lentiviral INs contain an additional $\mathrm{N}$-terminal extension domain [2]. The NTD adopts a zinc finger fold containing a conserved HHCC motif essential for activity [3-5]. The CCD contains a D,D-35-E motif which binds divalent metal ions within an RNase $\mathrm{H}$-like fold that comprises the active site [6-8]. The CTD adopts an SH3-like fold and is implicated in DNA binding $[9,10]$. Dimers of each isolated domain have been observed $[3,8,10-12]$ 
and recombinant full-length IN has been reported to exist in forms ranging from monomer to octamer [13-18].

IN carries out two catalytic reactions: 3 -processing and strand transfer [1], in a macromolecular complex consisting of multiple IN protomers, viral DNA, cofactors, and host cell proteins termed the intasome [14, 1925]. Early intasome structures were determined with IN from the prototype foamy virus (PFV) [26-30], revealing the structural details of enzymatic activity and the mechanism of action of the strand-transfer inhibitors (STIs), which displace the $3^{\prime}$ viral DNA end from the active site, rendering the intasome nonfunctional [22, 23, 31, 32]. STIs are in widespread clinical use [33], however, as with all antiretrovirals, development of resistance is a major barrier to durable inhibition of viral replication [34, 35].

PFV intasome structures and homology modeling [36, 37] have provided important insight into HIV-1 intasome function; however, PFV IN diverges significantly from HIV-1 IN in sequence identity, interdomain linker length, and the presence of an N-terminal extension domain [38]. Intasome structures from Rous sarcoma virus (RSV) [39], mouse mammary tumor virus (MMTV) [40], and Maedi-visna virus (MVV) [25] have furthered our understanding of HIV-1 IN. In contrast to PFV IN $[26,41]$, study of HIV-1 IN is challenging due to poor solubility and a propensity to aggregate [42, 43], along with inefficient catalysis in vitro [44-50]. Fusion of a small DNA-binding protein, Sso7d, that mimics the N-terminal extension domain of PFV to the N-terminus of HIV-1 IN improved catalysis and the solubility of HIV-1 intasomes [51], and enabled structural determination of the HIV-1 core intasome complex by cryo-electron microscopy (cryo-EM) [23, 24]. However, a native HIV-1 intasome structure remains elusive.

The first N-terminal residue of HIV-1 IN is a highly conserved phenylalanine [52-54] liberated by retroviral protease cleavage from the $\mathrm{C}$-terminus of reverse transcriptase. Viruses containing engineered substitutions at IN F1 are replication-incompetent [55], showing defects in reverse transcription and integration, characteristic of class II IN mutations such as those that disrupt the HHCC motif [56-59]. Another closely studied NTD substitution Y15A also affects reverse transcription and integration [60], and $\mathrm{IN}^{\mathrm{Y} 15 \mathrm{~A}}$ is hypo-oligomeric in solution [13, 61]. Isolated IN NTD ${ }^{\mathrm{Y} 15 \mathrm{~A}}$ is structurally constrained, adopting only one of two NTD conformational states (the E form) [62] while the wild type NTD adopts both the $\mathrm{E}$ and $\mathrm{D}$ forms [3]. Conformational transition between $\mathrm{E}$ and $\mathrm{D}$ forms involves significant structural rearrangements in the NTD, including a change in the length of the a 1 helix by 6 residues [3]. The aberrant phenotypes caused by substitutions at F1 and Y15 led us to investigate the structure and function of the HIV-1 NTD in more detail.

IN is often produced for laboratory studies by bacterial overexpression in vitro with an $\mathrm{N}$-terminal methionine (IN MF) $[61,63,64]$ or as an N-terminal fusion protein, such as the Sso7d-IN fusion [23, 24, 51]. Solution structures of the isolated NTD were determined from constructs purified with a cleavable $\mathrm{N}$-terminal affinity tag $[3,65]$, so that thrombin cleavage of the fusion protein left three residues (G-S-H-) preceding F1 (IN GSH). In the solution structure of IN $\mathrm{GSH}_{\mathrm{NTD}}$ [3], the backbone carbonyl of F1 contributes the first hydrogen bond of the a1 helix. The solution structure of another variant, IN $\mathrm{GSH}_{\mathrm{NTD}}^{\mathrm{H} 12 \mathrm{C}}$, which contains a substitution in the HHCC $\mathrm{Zn}$-binding motif, shows a different $\mathrm{N}$-terminal structure: the carbonyl of F1 is not involved in a hydrogen bond, L2 is displaced, and the a1 helix begins with G4 [65]. The only crystal structure containing the HIV- 1 IN $_{\text {NTD }}$ (PDB: 1K6Y) [66] consists of a two-domain truncated form (NTD-CCD) also purified using an N-terminal affinity tag and subsequent thrombin cleavage, leaving 3 residues (G-S-H-) preceding F1 [43, 66]. In this case as well, the a1 helix is shortened, suggesting that the extra N-terminal residues might be disrupting native folding of the a1 helix.

Four NTDs in two structurally distinct positions exist in the HIV-1 core intasome complex cryo-EM structures determined with Sso7d-IN [23, 24]. One NTD, positioned close to the viral DNA and the CCD responsible for catalysis, forms NTD-NTD interactions in the dodecameric HIV-1 intasome and the hexadecameric MVV intasome [25]. The a1 helix of this NTD is shortened in the first HIV-1 tetrameric intasome structure where it begins with Asp 3 [24]. The a1 helix is extended in four of five recent intasome structures, with only one structure showing partial disruption [23]. The second NTD does not interact with the viral DNA and is distant from the active site. This NTD does not form NTD-NTD interactions in dodecameric or hexadecameric intasomes and shows a range of a1 helical structures: disordered, partially unstructured, and extended [23]. Intasomes of a closely-related simian immunodeficiency virus were prepared with IN purified with an N-terminal affinity tag and subsequent human rhinovirus $3 \mathrm{C}$ protease cleavage, leaving 3 residues (G-P-G-) preceding F1 [22]. The NTDs in these structures show extended a1 helices.

In this paper, we report a purification scheme of wild type IN with phenylalanine as the $\mathrm{N}$-terminal residue (IN 1F), and associated alterations in the $\mathrm{N}$-terminal structure and IN function. IN 1F was purified with an $\mathrm{N}$-terminal affinity tag, which, when removed, leaves phenylalanine at position 1 . We report a two-domain NTD-CCD crystal structure of IN 1F that shows a 
continuous helical fold beginning with the backbone carbonyl of F1, in contrast to the existing IN $\mathrm{GSH}_{\mathrm{NTD}-\mathrm{CCD}}$ structure [66]. IN 1F also shows greater concerted integration activity in vitro compared to IN GSH and IN MF. IN $1 F$ is altered in its sensitivity to inhibitors, showing decreased sensitivity to the strand-transfer inhibitor raltegravir and increased sensitivity to allosteric integrase inhibitors (ALLINIs). Biophysical characterization reveals that IN $1 \mathrm{~F}$ has oligomeric properties distinct from previously studied recombinant IN constructs. We propose that HIV-1 IN 1F more closely recapitulates the structure and functions of IN found in authentic HIV infection.

\section{Methods}

\section{Construction of IN expression vectors}

The NL4-3 HIV-1 IN coding sequence was amplified by $\mathrm{PCR}$, fused to an N-His7-Flag-Sumo tag using 4-primer pcr, and cloned into a pCDFDuet expression vector. The fusion junction contains the sequence "G-G-F", where cleavage by the SUMO protease Ulp1 occurs after the second glycine, liberating IN with a phenylalanine at position 1. IN GSH and IN MF were created by insertion of additional codons preceding the native phenylalanine by inverse PCR (IN GSH) or site-directed mutagenesis (IN MF). IN $1 F$ FTD-CCD F185139D was constructed by truncation of the full-length construct and insertion of a synthetic cassette containing the amino acid substitutions. The lens epithelium derived growth factor (LEDGF) integrase binding domain (IBD) (residues 347-471) was cloned into a pETDuet expression vector with the Mxe intein, a chitin binding domain, and a His6 tag as previously described [67].

\section{Protein expression and purification}

IN constructs were expressed as previously described with some modification [61, 64, 67-69]. Expression plasmids were transformed into $E$. coli BL21(DE3) and grown in $800 \mathrm{~mL}$ of $2 \times \mathrm{YT}$ at $37^{\circ} \mathrm{C}$ to an optical density of $1.8-$ 2.2. Expression was induced by addition of isopropyl$\beta$-D-1-thiogalactopyranoside (IPTG) and allowed to continue for $5 \mathrm{~h}$ at $20^{\circ} \mathrm{C}$. Bacteria were then pelleted and frozen at $-80^{\circ} \mathrm{C}$.

Full-length IN constructs were purified as described previously $[64,67,69]$. Briefly, lysates were loaded onto nickel-nitrilotriacetic acid resin (Qiagen). Fusion proteins were eluted with $20 \mathrm{mM}$ HEPES-NaOH pH 7.5, $1 \mathrm{M}$ $\mathrm{NaCl}, 7 \mathrm{mM}$ 3-[(3-cholamidopropyl)dimethylammonio]1-propanesulfonate (CHAPS), $10 \mu \mathrm{M} \mathrm{ZnOAc}, 5 \mathrm{mM}$ $\beta$-mercaptoethanol, and $250 \mathrm{mM}$ imidazole. Fusion proteins were liberated from IN by overnight cleavage with the SUMO protease Ulp1 (Life Sensors) at $4{ }^{\circ} \mathrm{C}$, with simultaneous dialysis against $20 \mathrm{mM}$ HEPES-NaOH pH 7159d $\mathrm{M} \mathrm{NaCl}, 7 \mathrm{mM}$ CHAPS, $10 \mu \mathrm{M} \mathrm{ZnOAc} 2$, and $5 \mathrm{mM}$ $\beta$-mercaptoethanol. The affinity tag was separated from IN by a second nickel-nitrilotriacetic acid purification step and further purified using a Superdex 75 HiLoad 16/60 column (GE Healthcare) at room temperature, eluted isocratically in $20 \mathrm{mM}$ HEPES-NaOH pH 7.5, $1 \mathrm{M} \mathrm{NaCl}, 7 \mathrm{mM}$ CHAPS, $10 \mu \mathrm{M} \mathrm{ZnOAc}$, and $2 \mathrm{mM} \mathrm{d}$ ithiothreitol (DTT). IN 1F F185K, W131D, F139D was lysed in $50 \mathrm{mM}$ sodium/potassium phosphate $\mathrm{pH} 7.0,500 \mathrm{mM}$ $\mathrm{NaCl}, 2 \mathrm{mM} \beta$-mercaptoethanol, and $10 \mathrm{mM}$ imidazole, loaded onto nickel-nitrilotriacetic acid resin, and eluted with $50 \mathrm{mM}$ sodium/potassium phosphate $\mathrm{pH}$ 7.0, $500 \mathrm{mM} \mathrm{NaCl}, 2 \mathrm{mM} \beta$-mercaptoethanol, and $250 \mathrm{mM}$ imidazole. The affinity tag was liberated from IN by overnight cleavage with the SUMO protease Ulp1, with simultaneous dialysis against $20 \mathrm{mM}$ sodium/potassium phosphate $\mathrm{pH} 7.0,500 \mathrm{mM} \mathrm{NaCl}$, and $\beta$-mercaptoethanol. The affinity tag was separated from IN by a second nickel-nitrilotriacetic acid purification step and further purified using a Superdex 75 HiLoad 16/60 column (GE Healthcare) at room temperature, eluted isocratically in $20 \mathrm{mM}$ HEPES- $\mathrm{NaOH} \mathrm{pH} 7.5$, $500 \mathrm{mM} \mathrm{NaCl}$, and $2 \mathrm{mM} \beta$-mercaptoethanol. IN was concentrated at $4{ }^{\circ} \mathrm{C}$ in an Amicon Ultra-15 (Millipore), glycerol was added to a final concentration of $10 \%(\mathrm{w} / \mathrm{v})$, and aliquots were flash-frozen in liquid nitrogen for storage at $-80^{\circ} \mathrm{C}$.

LEDGF IBD was purified using nickel-nitrilotriacetic acid (Qiagen) and chitin (New England Biolabs) resins. After fusion proteins were liberated by intein cleavage in $50 \mathrm{mM}$ DTT overnight at $4{ }^{\circ} \mathrm{C}$, LEDGF IBD preparations were further purified using a Superdex 75 HiLoad 16/60 column (GE Healthcare) at room temperature, eluted isocratically in $20 \mathrm{mM}$ HEPES-NaOH pH 7.0, $1 \mathrm{M} \mathrm{NaCl}, 7 \mathrm{mM}$ CHAPS, $10 \mu \mathrm{M} \mathrm{ZnOAc} 2$, and $10 \mathrm{mM}$ $\beta$-mercaptoethanol. The LEDGF IBD was concentrated at $4{ }^{\circ} \mathrm{C}$ in an Amicon Ultra-15 (Millipore), glycerol was added to a final concentration of $10 \%(\mathrm{w} / \mathrm{v})$, and aliquots were flash-frozen in liquid nitrogen for storage at $-80^{\circ} \mathrm{C}$.

\section{Crystallization and structure determination}

Crystals were grown by vapor diffusion as previously described [66]. Briefly, $4 \mu \mathrm{L}$ of protein at $5-10 \mathrm{mg} / \mathrm{mL}$ in $0.5 \mathrm{M} \mathrm{NaCl}, 20 \mathrm{mM}$ HEPES $\mathrm{pH} 7.5,100 \mu \mathrm{M} \mathrm{ZnCl}_{2}$, $5 \%(\mathrm{w} / \mathrm{v})$ glycerol, and $5 \mathrm{mM}$ DTT was mixed with $4 \mu \mathrm{L}$ of reservoir solution containing $0.7 \mathrm{M} \mathrm{NaH}_{2} \mathrm{PO}_{4}, 1.0 \mathrm{M}$ $\mathrm{K}_{2} \mathrm{HPO}_{4}$ and $0.1 \mathrm{M}$ acetate $\mathrm{pH}$ 4.6. Two crystal forms were observed, flat hexagons and long tetragonal crystals, with only the latter exhibiting high resolution diffraction. Crystals were cryo-protected in $0.8 \mathrm{M} \mathrm{NaH}_{2} \mathrm{PO}_{4}, 1.2 \mathrm{M}$ $\mathrm{K}_{2} \mathrm{HPO}_{4}, 0.2 \mathrm{M} \mathrm{NaCl}$, and $20 \%$ glycerol and flash-frozen in liquid nitrogen. Diffraction data was collected at $100 \mathrm{~K}$ 
using an Eiger 9M pixel-array detector on beamline 17-ID-1 (AMX) at Brookhaven National Laboratory [70, 71].

Diffraction data were reduced with DIALS [72]. Molecular replacement, refinement, and the generation of simulated annealing omit maps were carried out in Phenix [73]. The structure was solved by molecular replacement using $1 \mathrm{~K} 6 \mathrm{Y}$ as a search model. The asymmetric unit contained four monomers (each containing a $\mathrm{Zn}^{2+}, \mathrm{K}^{+}$, and phosphate ion) and 226 waters. The structure was refined to a $\mathrm{R}$ and $\mathrm{R}_{\text {free }}$ of $22.5 \%$ and $25.3 \%$, respectively. Molecular models were visualised with Pymol [74] and secondary structure was analyzed with Define Secondary Structure of Proteins (DSSP) [75, 76].

\section{Integrase $3^{\prime}$-processing assay}

The $3^{\prime}$-processing assay was adapted from those described previously [77, 78]. HIV integrase at $60 \mu \mathrm{M}$ in 20 mM HEPES-NaOH pH 7.5, $1 \mathrm{M} \mathrm{NaCl}, 7$ mM CHAPS, $10 \mathrm{mM}$ DTT, and $10 \mu \mathrm{M} \mathrm{Zn}(\mathrm{OAc})_{2}$ was diluted to a final assay concentration of $400 \mathrm{nM}$ with $20 \mathrm{mM}$ HEPES$\mathrm{NaOH}$ pH 7.5, $100 \mathrm{nM}$ Alexafluor 488-labeled LTR substrate, $50 \mathrm{mM} \mathrm{NaCl}, 10 \mathrm{mM} \mathrm{MgCl} 2$ or $\mathrm{MnCl}_{2}, 10 \mu \mathrm{M}$ $\mathrm{Zn}(\mathrm{OAc})_{2}$, and $10 \mathrm{mM} \mathrm{DTT}$. Final assay conditions were identical for IN 1F, IN GSH, and IN MF. Unprocessed U5 LTR substrates with a $3^{\prime}$ Alexafluor $488 N$-hydroxysuccinimide (NHS) ester label were prepared by annealing the following oligonucleotides (Integrated DNA Technologies):

- 5'-ACCCTTTTAGTCAGTGTGGAAAATCTCTAG CAGT-Alexa488-3'

- 5'-ACTGCTAGAGATTTTCCACACTGACTAAAA GGGT-3'.

Reactions were incubated at $37^{\circ} \mathrm{C}$. SDS was added to a final concentration of $0.25 \%$ to stop the reaction and liberate cleaved dinucleotide. After $15 \mathrm{~min}$, fluorescence polarization was analyzed with a plate reader (Victor 3V, Perkin Elmer). Significance was evaluated by two-way ANOVA with $P$ values reported from Tukey's multiple comparisons test. Data analysis was carried out in Prism (GraphPad).

\section{Integrase strand-transfer assay}

The strand-transfer assay was adapted from those described previously $[48,61,79,80]$.

$\mathrm{HIV}$ integrase at $60 \mu \mathrm{M}$ in $20 \mathrm{mM}$ HEPES-NaOH pH 7.5, $1 \mathrm{M} \mathrm{NaCl}, 7 \mathrm{mM}$ CHAPS, $10 \mathrm{mM}$ DTT, and $10 \mu \mathrm{M}$ $\mathrm{Zn}(\mathrm{OAc})_{2}$ was diluted to a final assay concentration of $3 \mu \mathrm{M}$ with $20 \mathrm{mM}$ HEPES-NaOH pH 7.5, $0.5 \mu \mathrm{M}$ Alexafluor 488-labeled LTR substrate, $0.5 \mu \mathrm{M}$ LEDGF IBD, $50-250 \mathrm{mM} \mathrm{NaCl}, 10 \mathrm{mM} \mathrm{MgCl}_{2}$ or $\mathrm{MnCl}_{2}$, and $10 \mu \mathrm{M}$
$\mathrm{Zn}(\mathrm{OAc})_{2}$. Final assay conditions were identical for IN 1F, IN GSH, and IN MF. Processed U5 LTR substrates with a $5^{\prime}$ Alexafluor $488 \mathrm{~N}$-hydroxysuccinimide (NHS) ester label were prepared by annealing the following oligonucleotides (Integrated DNA Technologies):

\section{- 5'-Alexa488-ACCCTTTTAGTCAGTGTGGAA AATCTCTAGCA-3' \\ - 5'-ACTGCTAGAgAT TTTCCACACTGACTA AAAGGGT-3'.}

After $30 \mathrm{~min}$ at $37{ }^{\circ} \mathrm{C}, 15 \mathrm{nM}$ pUC19 plasmid was added. Reactions were carried out for $1-4$ h at $37{ }^{\circ} \mathrm{C}$, then quenched using 0.5\% SDS, $15 \mathrm{mM}$ EDTA, and $1 \mathrm{mg} / \mathrm{mL}$ proteinase $\mathrm{K}$ for $30 \mathrm{~min}$ at $37{ }^{\circ} \mathrm{C}$. Reaction products were separated on $1.5 \%$ agarose gels in Trisacetate buffer and imaged using a Typhoon (Amersham) imager. Gels were then stained with ethidium bromide and imaged using a Gel Doc (Bio-Rad) imager. Reaction products were quantified by ImageJ and data analysis was carried out in Prism (GraphPad). Significance was evaluated by two-way ANOVA with P values reported from Tukey's multiple comparisons test. Dose-response curve fits were performed in Prism (GraphPad) using a three-parameter logistic regression with the Hill slope fixed at -1 . The integrase inhibitor raltegravir was a gift from Merck.

\section{Aggregation assay for ALLINIs}

Assays were performed as previously described [61, 63] with some modification. Final reaction conditions were $20 \mathrm{mM}$ HEPES-NaOH pH 7.5, $15 \mu \mathrm{M}$ IN, 250-1000 mM $\mathrm{NaCl}, 7 \mathrm{mM}$ CHAPS, and $30 \mu \mathrm{M}$ ALLINI. The ALLINIs BI-224436, BI-D, and CX04328 (HIV-1 integrase inhibitor 2) were purchased from MedChemExpress and resuspended in DMSO. Turbidity was measured after $20 \mathrm{~min}$ as the absorbance of the reaction solution at $405 \mathrm{~nm}$ in a plate reader (Victor 3V, Perkin Elmer). Significance was evaluated by two-way ANOVA with $\mathrm{P}$ values reported from Tukey's multiple comparisons test.

\section{Size-exclusion chromatography in-line with multi-angle light scattering (SEC-MALS)}

Absolute molecular weights were determined by multiangle light scattering coupled with refractive interferometric detection (Wyatt Technology Corporation) and a Superdex 200 10/300 column (GE Healthcare) at $25^{\circ} \mathrm{C}$ equilibrated in $20 \mathrm{mM}$ HEPES-NaOH pH 7.5, $500 \mathrm{mM}-1 \mathrm{M} \mathrm{NaCl}, 7 \mathrm{mM}$ CHAPS, $10 \mu \mathrm{M} \mathrm{ZnOAc}$, and $10 \mu \mathrm{M} \beta$-mercaptoethanol, as previously described [64]. 


\section{Sedimentation velocity analytical ultracentrifugation (SV-AUC)}

SV-AUC experiments were performed at $25{ }^{\circ} \mathrm{C}$ with an XL-A analytical ultracentrifuge (Beckman-Coulter) and a TiAn60 rotor with two-channel charcoal-filled epon centerpieces and quartz windows. Experiments were performed in $20 \mathrm{mM}$ HEPES-NaOH $\mathrm{pH}$ 7.5, $1 \mathrm{M} \mathrm{NaCl}, 7 \mathrm{mM}$ CHAPS, $10 \mu \mathrm{M} \mathrm{ZnOAc}$, and $10 \mu \mathrm{M}$ $\beta$-mercaptoethanol. Complete sedimentation velocity profiles were collected every $30 \mathrm{~s}$ for 200 boundaries at $40,000 \mathrm{rpm}$. Data were fit using the $c(s)$ distribution model of the Lamm equation as implemented in the program SEDFIT [81]. After optimizing meniscus position and fitting limits, the sedimentation coefficients and best-fit frictional ratio $\left(f / f_{0}\right)$ were determined by iterative least squares analysis. Sedimentation coefficients were corrected to $s_{20, w}$ based on the calculated solvent density $(\rho)$ and viscosity $(\eta)$ derived from chemical composition by the program SEDNTERP [82].

\section{Sedimentation equilibrium analytical ultracentrifugation (SE-AUC)}

SE-AUC experiments were performed with an XL-A analytical ultracentrifuge (Beckman-Coulter) and a TiAn60 rotor with two-channel charcoal-filled epon centerpieces and quartz windows. Data were collected at $4{ }^{\circ} \mathrm{C}$ with detection at $280 \mathrm{~nm}$ at multiple concentrations in $20 \mathrm{mM}$ HEPES-NaOH pH 7.5, $1 \mathrm{M} \mathrm{NaCl}, 7$ mM CHAPS, $10 \mu \mathrm{M}$ $\mathrm{ZnOAc}_{2}$, and $10 \mu \mathrm{M} \beta$-mercaptoethanol. Analyses were carried out using global fits to data acquired at multiple speeds for each concentration with strict mass conservation using the program SEDPHAT [83]. Error estimates for equilibrium constants were determined from a 1000-iteration Monte Carlo simulation. The partial specific volume $(\bar{v})$, solvent density $(\rho)$, and viscosity $(\eta)$ were derived from chemical composition by SEDNTERP [82]. SE-AUC data are summarized in Table 2.

\section{Results \\ Cloning and purification of HIV-1 integrase with a native N-terminus}

To determine the biochemical and structural properties of HIV-1 IN with a phenylalanine at the N-terminus, we cloned NL4-3 IN into an expression vector containing an $\mathrm{N}$-terminal His7-FLAG-SUMO tag immediately preceding F1. The SUMO protease Ulp1 cleaves at a G-G-/-X motif (with the cleavage site indicated by/, with $\mathrm{X}$ being any residue except proline) [84]. This allows for purification of wild-type IN with a native N-terminus ("IN 1F") by Ulp1 cleavage at the sequence $\mathrm{G}-\mathrm{G}-/-\mathrm{F}$ (Additional file 1: Figure S1). To compare to IN with a non-native $\mathrm{N}$-terminus, we inserted additional N-terminal residues preceding F1. IN GSH contains the three residues
(G-S-H) that remain after thrombin cleavage, as used to

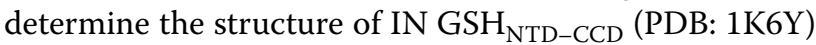
[66], and IN MF contains an N-terminal methionine found in constructs commonly used for bacterial overexpression [61, 63, 64]. A nickel-affinity step captures Ulp1 and the cleaved affinity tag and subsequent size-exclusion chromatography yields a highly pure final product (Additional file 1: Figure S1).

\section{Crystallization of an IN 1F NTD-CCD derivative}

To investigate structural differences between IN $1 \mathrm{~F}$ and IN GSH, we created an IN $1 F_{\text {NTD-CCD }}$ construct containing the same solubility-enhancing substitutions (W131D, F139D, and F185K) used to determine the structure of IN $\mathrm{GSH}_{\mathrm{NTD}-\mathrm{CCD}}$ [66]. Affinity purification, Ulp1 cleavage, and size-exclusion chromatography yielded a highly pure final product (Additional file 1: Figure S1) that readily crystallized as described previously [66]. The structure was solved by molecular replacement, using the existing NTD-CCD structure (PDB: 1K6Y) as a search model. Four copies of both the NTD and the CCD were present in the asymmetric unit (Fig. 1a), with the inter-domain linker (residues 47-55) unresolved in the electron density. In the structure of IN $\mathrm{GSH}_{\mathrm{NTD}-\mathrm{CCD}}$, each NTD is assigned to a "distal" position relative to the CCD (Additional file 2: Figure S2). However, in the crystal structure of the HIV-2 IN $_{\mathrm{NTD}-\mathrm{CCD}}$ complexed with the lens epithelium derived growth factor (LEDGF) integrase binding domain (IBD) (PDB: 3F9K) [85], the interdomain linker is well-defined in the electron density, placing the NTDs in a "proximal" position relative to the CCD (Additional file 2: Figure S2). This is also the favored position for the NTDs in small angle X-ray scattering (SAXS) analysis of IN NTD-CCD coexpressed with the LEDGF IBD [64]. In the IN $1 F_{\mathrm{NTD}-\mathrm{CCD}}$ structure, the unresolved 10-residue linker would be long enough to span the unobstructed distance of 28.7-31.8 A to position the NTDs in a "proximal" position. We have therefore defined the NTDs in the "proximal" orientation relative to the CCDs, as observed in the HIV-2 IN $_{\text {NTD-CCD }}$ structure (Fig. 1a). Crystallographic statistics are summarized in Table 1.

\section{Structure of the IN 1F NTD-CCD construct}

The overall structure of IN $1 \mathrm{~F}_{\mathrm{NTD}-\mathrm{CCD}}$ is highly similar

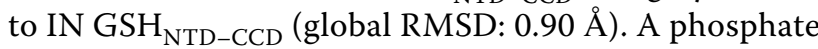
ion is found near the active site of each CCD. Each copy of the NTD folds into a 3-helix motif coordinating a $\mathrm{Zn}^{2+}$ ion with residues $\mathrm{H} 12, \mathrm{H} 16, \mathrm{C} 40$, and $\mathrm{C} 43$. A potassium ion is coordinated by the carbonyl oxygens of V37, A38, C40, C43. Close inspection of the N-terminus reveals differences between IN $1 F$ and IN GSH (Fig. 1b). In the asymmetric unit of IN 1F, two secondary structures are observed at the $\mathrm{N}$-terminus. The a1 


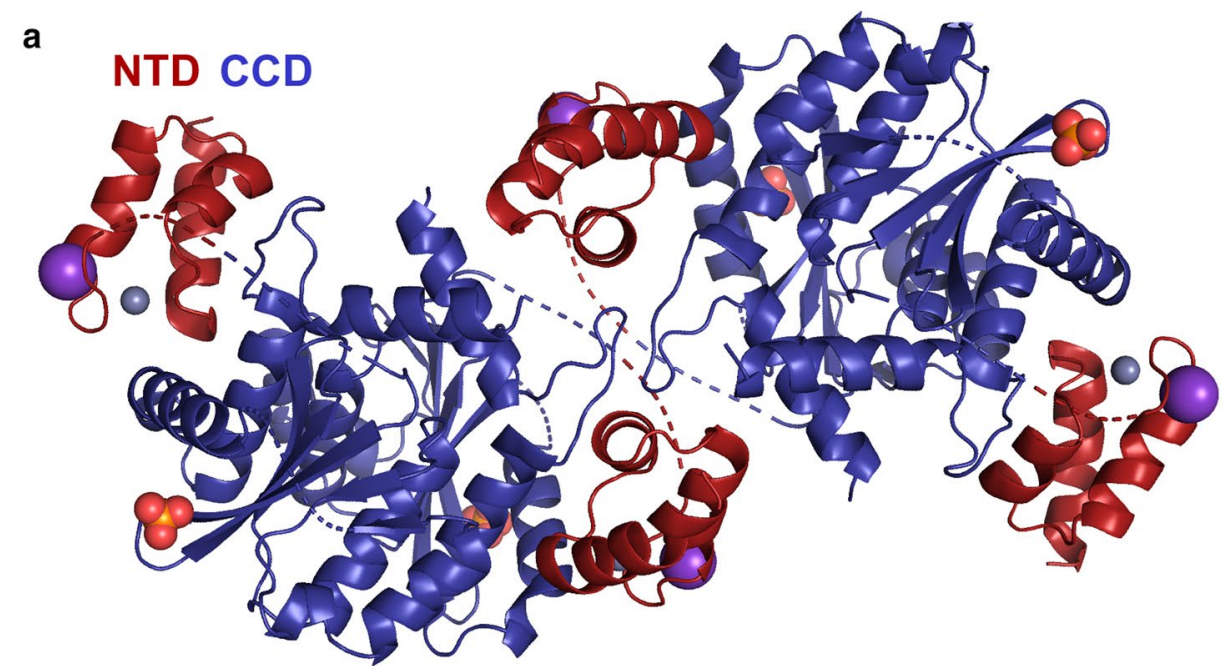

b

IN $1 F$ Chain A, C

Chain B, D

IN GSH
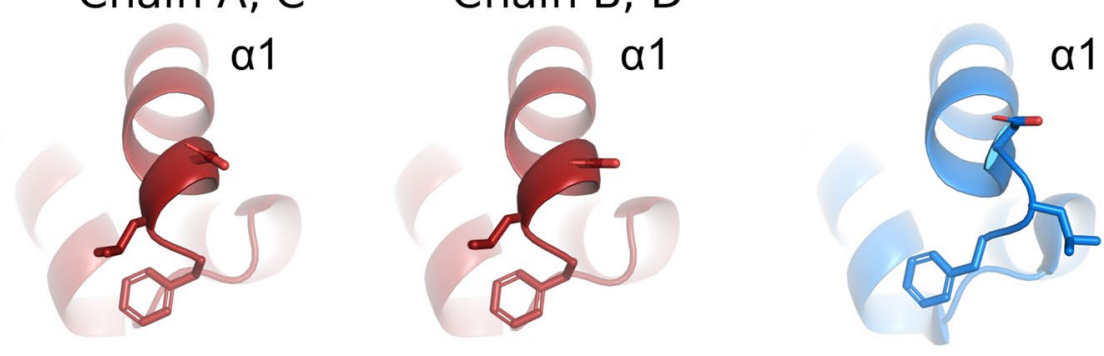

C
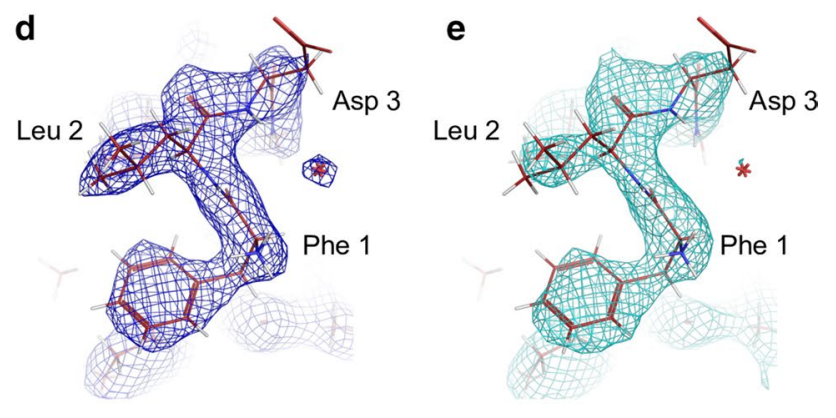

Phe 1

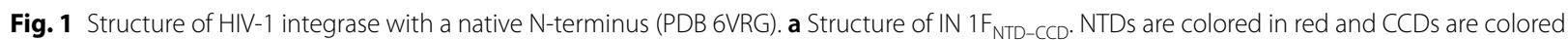
in blue. $\mathrm{Zn}^{2+}$ (grey), $\mathrm{K}^{+}$(purple), and phosphate (orange and red) atoms are shown as spheres. $\mathbf{b}$ Comparison of the a 1 helix between IN $1 \mathrm{~F}$ and IN GSH (PDB 1K6Y). The IN IF NTD adopts a helical structure starting from the carbonyl of F1. The IN GSH NTD shows a disruption of the a 1 helix. $\mathbf{c}$ View highlighting differences between IN IF and IN GSH at the N-terminus, with a deviation of $4.6 \AA$ in the peptide backbone at L2 and a $10.4 \AA$ deviation in side chain position. This change is accompanied by a flip of $\sim 180^{\circ}$ in the orientation of the N-terminus. 2Fo-Fc electron density (d) and simulated annealing omit (e) maps contoured at $1.5 \sigma$ unambiguously demonstrate the N-terminal structure of IN $1 \mathrm{~F}$

helix in chains $\mathrm{A}$ and $\mathrm{C}$ begins as a hydrogen-bonded turn at the backbone carbonyl of F1, while in chains $\mathrm{B}$ and $\mathrm{D}$, a canonical alpha helix begins at the backbone carbonyl of F1 (Fig. 1b, Additional file 3: Figure
S3). In IN GSH, the a1 helix does not begin until D3 due to a shift in the $\mathrm{L} 2$ side chain by $\sim 10 \AA$, accompanied by a $\sim 4.6 \AA$ displacement of the peptide backbone 
Table 1 Crystallographic statistics

\begin{tabular}{|c|c|}
\hline Data collection & Overall (highest shell) \\
\hline Space group & $\mathrm{P}_{4} \mathrm{2}_{1} 1$ \\
\hline Unit cell dimensions & $\begin{array}{l}102.919 \AA \times 102.919 \\
\AA \times 279.203 \AA ; 90^{\circ} \\
90^{\circ}, 90^{\circ}\end{array}$ \\
\hline Resolution range $(\AA)$ & $96.567-2.40$ \\
\hline$R_{\text {merge }}$ & $0.558(1.619)$ \\
\hline $\mathrm{R}_{\text {p.i.m. }}$ & $0.110(0.318)$ \\
\hline $\mathrm{CC}_{1 / 2}$ & $0.990(0.289)$ \\
\hline Multiplicity & $26.6(26.6)$ \\
\hline $1 / \sigma$ & $8.1(1.6)$ \\
\hline Completeness (\%) & $100(100)$ \\
\hline \multicolumn{2}{|l|}{ Refinement } \\
\hline Reflections (work) & 58,492 \\
\hline Reflections (free) & 1169 \\
\hline$R_{\text {work }}$ & $22.5 \%$ \\
\hline$R_{\text {free }}$ & $25.3 \%$ \\
\hline Protein atoms & 12,003 \\
\hline Ligand/ion atoms & 28 \\
\hline Water molecules & 226 \\
\hline R.m.s. bonds $(\AA)$ & 0.004 \\
\hline R.m.s. angles $\left(^{\circ}\right)$ & 0.589 \\
\hline \multicolumn{2}{|c|}{ Ramachandran plot (\%) } \\
\hline Favored & 98.49 \\
\hline Allowed & 1.51 \\
\hline Outliers & 0.00 \\
\hline
\end{tabular}

at L2 (Fig. 1b, c, Additional file 3: Figure S3). F1 is in a similar position in IN 1F and IN GSH, where it caps a hydrophobic core in the NTD made up of I5, L28, $\mathrm{P} 29$, and V32. The N-terminal amino group also differs between these two structures due to the peptide backbone displacement at L2. In IN GSH, the N-terminal amino group is oriented toward the $\mathrm{C}$-terminal end of the a 2 helix, whereas in IN $1 \mathrm{~F}$, it is flipped $\sim 180^{\circ}$ and oriented toward the a3 helix of a neighboring NTD. The same NTD-NTD interface is observed in dodecameric HIV-1, hexadecameric MVV, and SIV intasome structures [22-25], and the NTDs modeled at this position adopt extended a 1 helical structures in four of six structures (Additional file 3: Figure S3). The NTDs that do not form an NTD-NTD interface show a variety of structures: disordered, partially unstructured, and extended (Additional file 3: Figure S3). Difference maps and simulated annealing omit maps calculated around the $\mathrm{N}$-terminus of each protomer of the IN $1 \mathrm{~F}_{\mathrm{NTD}-\mathrm{CCD}}$ structure confirmed the observed differences between the N-termini of IN 1 F and IN GSH (Fig. 1d, e).

\section{Activity of IN $1 \mathrm{~F}$ in vitro}

IN carries out two catalytic functions, $3^{\prime}$-processing and strand transfer, which can be replicated in vitro using fluorescently-labeled oligonucleotides that mimic the viral long terminal repeat (LTR). To assay $3^{\prime}$-processing, we used a $3^{\prime}$-fluorescently-labeled doublestranded oligonucleotide mimicking the viral LTR to monitor release of the terminal dinucleotide $\left(5^{\prime}-\mathrm{GT}-3^{\prime}\right)$ using fluorescence polarization [77]. The unprocessed oligonucleotide emits highly polarized fluorescence. Upon cleavage by IN, the released dinucleotide emits fluorescence with low polarization. In the presence of $\mathrm{Mg}^{2+}$ and $\mathrm{Mn}^{2+}$, IN 1F, IN GSH, and IN MF showed similar 3 '-processing activities (Fig. 2).

To assay strand transfer activity, we used $5^{\prime}$-fluorescently-labeled oligonucleotides mimicking the viral LTR and a supercoiled plasmid mimicking nucleosomal DNA (Fig. 3a). Concerted integration of two viral LTRs by IN results in linearization of the supercoiled plasmid and incorporation of the fluorescent label. Strandtransfer activity in the presence of $\mathrm{Mg}^{2+}$ and $\mathrm{Mn}^{2+}$ was influenced by $\mathrm{NaCl}$ concentration, with the highest level of concerted integration occurring at $150 \mathrm{mM}$ $\mathrm{NaCl}$ in the presence of $\mathrm{Mg}^{2+}$ and $200-250 \mathrm{mM} \mathrm{NaCl}$ in the presence of $\mathrm{Mn}^{2+}$ (Additional file 4: Figure S4). In identical assay conditions, IN $1 \mathrm{~F}$ showed superior concerted integration activity, resulting in the formation of 2 LTR coupled products, as compared to IN GSH and IN MF at all time points measured (Fig. 3b, c). This difference was observed in the presence of either $\mathrm{Mg}^{2+}$ or $\mathrm{Mn}^{2+}$.

A partial reaction, the integration of a single LTR oligo, results in relaxation of the supercoiled plasmid and incorporation of the fluorescent label. Quantification of the fluorescently tagged, relaxed-circular plasmid indicates single-ended integration activity. Single-end activity, resulting in the formation of tagged circle products, was not improved by IN $1 \mathrm{~F}$ as compared to IN GSH or IN MF (Fig. 3c).

Treatment with the strand transfer inhibitor raltegravir more potently inhibited both the single-strand and concerted integration activity of IN GSH and IN MF as compared to IN 1F (Fig. 3d, Additional file 5: Figure S5). The $\mathrm{IC}_{50}$ for inhibiting concerted integration was 125 nM (95\% CI 83-186 nM), 109 nM (95\% CI 83-142 nM), and $370 \mathrm{nM}$ (95\% CI 270-508 nM) for IN GSH, IN MF, IN 1F, respectively. The $\mathrm{IC}_{50}$ for inhibiting single-strand integration was 253 nM (95\% CI 202$318 \mathrm{nM}), 223 \mathrm{nM}$ (95\% CI 141-356 nM), and $1.13 \mu \mathrm{M}$ (95\% CI 0.73-1.8 $\mu \mathrm{M}$ ) for IN GSH, IN MF, and IN 1F, respectively. 
a
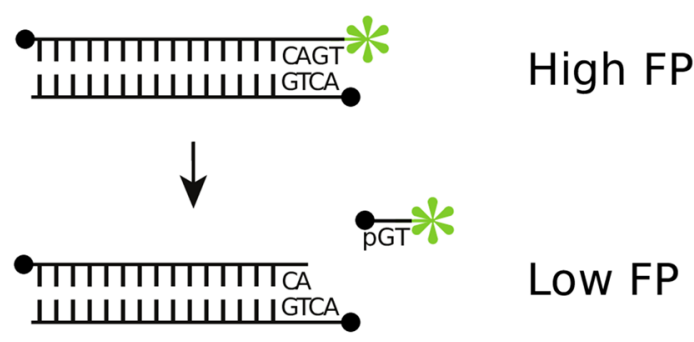

b
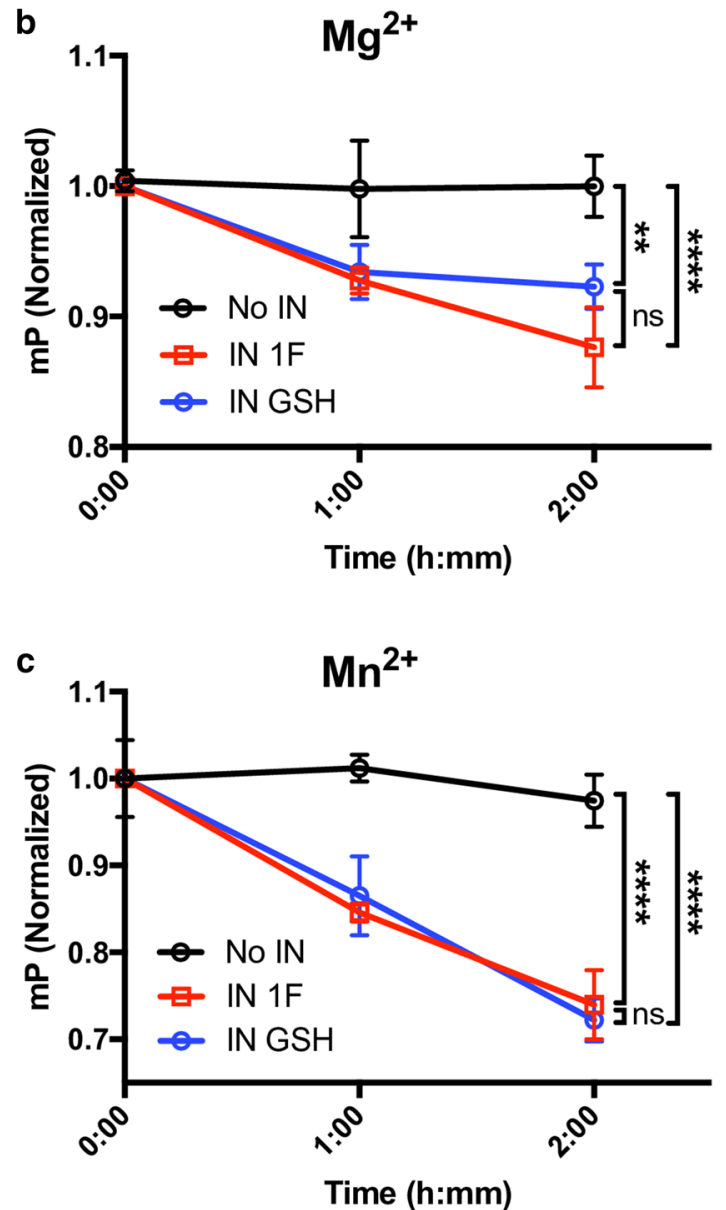
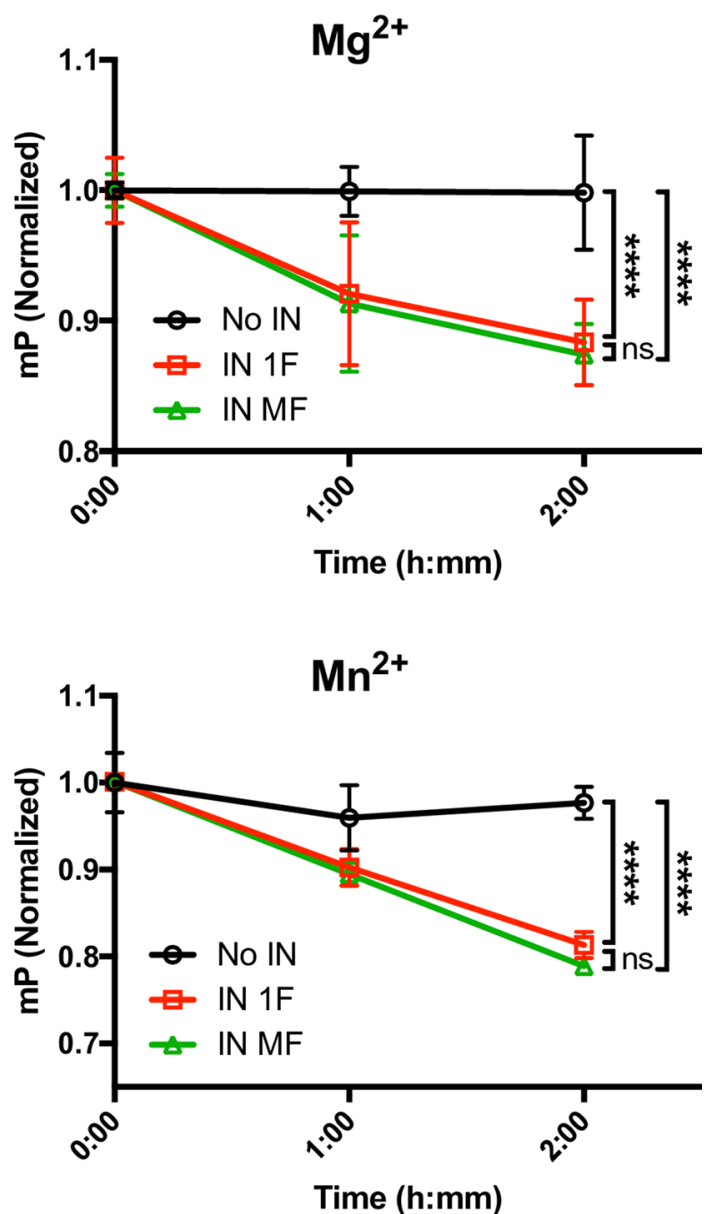

Fig. 2 3'-processing activity in vitro. a Diagram of 3'-processing fluorescence polarization assay. The double stranded oligo containing a $3^{\prime}$ fluorescent label exhibits high fluorescence polarization. Cleavage and release of the terminal dinucleotide causes a decrease in fluorescence polarization. $5^{\prime}$-ends are designated by filled circles and the fluorophore is designated by the green star. $\mathbf{b} 3^{\prime}$-processing activity of IN $1 \mathrm{~F}$ compared to IN GSH (left) and IN $1 \mathrm{~F}$ compared to IN MF (right) in the presence of $\mathrm{Mg}^{2+}$. c $3^{\prime}$ processing activity of IN $1 \mathrm{~F}$ compared to IN GSH (left) and IN $1 \mathrm{~F}$ compared to IN MF (right) in the presence of $\mathrm{Mn}^{2+}$. Data are plotted as mean \pm SD. ** Denotes $P<0.01$ and ${ }^{* * *}$ denotes $P<0.0001$

\section{Response of IN 1F and IN MF to ALLINIs}

The allosteric inhibitors of integrase (ALLINIs) [8688 ] are a class of small molecule inhibitors that block the interaction of IN with LEDGF and cause aberrant aggregation of IN [61, 63, 89]. ALLINIs aggregate recombinant IN in vitro, causing turbidity that can be measured by light scattering [61, 63, 64]. Using this approach, we measured the sensitivity of IN $1 \mathrm{~F}$, IN
GSH, and IN MF to ALLINIs (Fig. 4). ALLINI-induced aggregation is $\mathrm{NaCl}$-dependent, so we tested aggregation at $\mathrm{NaCl}$ concentrations from $250 \mathrm{mM}$ to $1 \mathrm{M}$. At $1 \mathrm{M} \mathrm{NaCl}$, no aggregation was observed by the ALLINIs BI-224436 [87], BI-D [90], or CX04328 (Compound 6 from Christ et al. [86]). At $\mathrm{NaCl}$ concentrations where ALLINI-induced aggregation was observed, ALLINIs induced equal or greater aggregation of IN $1 \mathrm{~F}$ as 
compared to IN GSH or IN MF. BI-224436, BI-D, and CX04328 aggregated IN $1 \mathrm{~F}$ more than IN GSH at 300$500 \mathrm{mM} \mathrm{NaCl}, 300-400 \mathrm{mM} \mathrm{NaCl}$, and $300-500 \mathrm{mM}$ $\mathrm{NaCl}$, respectively. Significant ALLINI-induced aggregation of IN GSH was only observed at $250 \mathrm{mM} \mathrm{NaCl}$, where IN $1 \mathrm{~F}$ was observed to aggregate in the absence of ALLINI. BI-224436, BI-D, and CX04328 aggregated IN $1 F$ more than IN MF from 350 to $500 \mathrm{mM} \mathrm{NaCl}$, $350-400 \mathrm{mM}$, and $500 \mathrm{mM} \mathrm{NaCl}$, respectively. At lower $\mathrm{NaCl}$ concentrations, ALLINIs induced aggregation of IN $1 F$ and IN MF to an equal extent.

\section{Solution properties of $\mathrm{IN}$ with a native $\mathrm{N}$-terminus}

One possible explanation for the improved activity of IN $1 \mathrm{~F}$ is that folding associated with the native $\mathrm{N}$-terminal sequence changes the oligomerization state. To investigate this possibility, we analyzed IN $1 F$ and IN MF by size-exclusion chromatography in line with multi-angle light scattering (SEC-MALS) to determine the oligomeric state in solution. Both IN 1F and IN MF showed mass profiles consistent with a monomer-dimer transition (32-64 kD, expected MW of monomer: $32 \mathrm{kD}$ ) at eluted concentrations of $\sim 8-10 \mu \mathrm{M}$, as well as retention times consistent with a mixture of monomers and dimers (Fig. 5a). Sedimentation velocity analytical ultracentrifugation (SV-AUC) experiments performed at similar concentrations and temperatures confirmed the presence of monomers and dimers with the presence of two discrete species at $\sim 2.8 \mathrm{~S}$ and $\sim 4 \mathrm{~S}$, respectively (Fig. $5 \mathrm{~b}$ ). Sedimentation equilibrium analytical ultracentrifugation (SEAUC) analysis at $4{ }^{\circ} \mathrm{C}$ and similar concentrations also confirmed the presence of monomers and dimers, and global fitting of a monomer-dimer equilibrium yielded a $\mathrm{K}_{\mathrm{d}}$ of $60 \pm 6 \mu \mathrm{M}$ and $127 \pm 23 \mu \mathrm{M}$ for IN $1 \mathrm{~F}$ and IN MF, respectively (Fig. 5c, Table 2). An attempt to fit a dimertetramer equilibrium could only be accomplished with a $K_{d}>1 \mathrm{mM}$. Therefore, no evidence of tetramers was observed by three biophysical methods, in contrast to prior studies performed under similar conditions with IN expression constructs with an $\mathrm{N}$-terminal methionine $[61,63,64], \mathrm{N}$-terminal thrombin [42], or human rhinovirus $3 C$ protease $[13,85]$ cleavage sequences.

The monomer-dimer behavior of IN $1 \mathrm{~F}$ in solution also differs from IN with an $\mathrm{N}$-terminal methionine, C-terminal intein cleavage site, and the solubility-enhancing substitution $\mathrm{F} 185 \mathrm{H}$, which exists as a mixture of dimers and tetramers in solution $[61,64]$ and is replication-competent in virus [91]. Introduction of the $\mathrm{F} 185 \mathrm{H}$ substitution into IN $1 \mathrm{~F}\left(\mathrm{IN} 1 \mathrm{~F}^{\mathrm{F} 185 \mathrm{H}}\right)$ resulted in the formation of dimers and a spectrum of higher-order aggregates in solution, as determined by SEC-MALS (Additional file 6: Figure $\mathrm{S6}$ ). IN $1 \mathrm{~F}^{\mathrm{F} 185 \mathrm{H}}$ retained similar $3^{\prime}$-processing activity as compared to IN $1 \mathrm{~F}$, but showed a significant decrease in single strand and concerted strand transfer activity (Additional file 6: Figure S6), indicating the effect of the oligomeric state of IN on strand transfer activity.

\section{Discussion}

In this paper, we report the construction and purification of IN with a native N-terminus (IN 1F). The crystal structure of $I N 1 F_{N T D-C C D}$ reveals an extended a1 helix starting with F1, as compared to IN $\mathrm{GSH}_{\mathrm{NTD}-\mathrm{CCD}}$ with a shortened helix. Despite the remainder of the structure showing little to no difference, this change in the $\mathrm{N}$-terminus is sufficient to improve concerted integration activity. In contrast, the $3^{\prime}$-processing and single strand integration activities were not affected. We also observed a change in sensitivity to IN-targeting antiretroviral drugs. IN $1 \mathrm{~F}$ was less sensitive to the STI raltegravir and more sensitive to ALLINI-induced aggregation. We suggest that IN $1 \mathrm{~F}$ will be useful in studies of IN function and response to inhibitors in the future.

(See figure on next page.)

Fig. 3 Strand transfer activity in vitro. a Diagram of gel-based strand transfer assay. A pre-processed double-stranded oligo containing a $5^{\prime}$ fluorescent label is integrated into a supercoiled target plasmid (pUC19) in the presence of integrase and cofactor $\left(\mathrm{Mg}^{2+}\right.$ or $\left.\mathrm{Mn}^{2+}\right)$. Single strand integration results in the formation of a tagged circle product accompanied by the relaxation of supercoiling. Concerted integration results in the formation of a 2 LTR coupled product, accompanied by the linearization of the plasmid. Reaction products are separated by agarose gel electrophoresis. b Example gels of IN 1 F and IN MF strand transfer activity. The slowest-migrating band represents single strand integration events (tagged circle) with the linearized concerted integration product (2 LTR coupled) migrating further. The supercoiled target plasmid is visible in the ethidium bromide stain as the furthest-migrating band. Unintegrated fluorescent oligo is observed at the bottom of the gel. c Quantification of IN IF and IN GSH strand transfer activity. Single strand integration events are shown in the top panels and concerted integration events are shown in the bottom panels. IN 1F shows greater concerted integration activity than IN GSH in the presence of either $\mathrm{Mg}^{2+}$ or $\mathrm{Mn}^{2+}$. $\mathbf{d}$ Quantification of IN $1 \mathrm{~F}$ and IN MF strand transfer activity. Single strand integration events are shown in the top panels and concerted integration events are shown in the bottom panels. IN $1 F$ shows greater concerted integration activity than IN MF in the presence of either $\mathrm{Mg}^{2+} \mathrm{or} \mathrm{Mn}^{2+}$. e Inhibition of strand transfer activity by raltegravir. Raltegravir more potently inhibits both the single strand (left) and concerted integration (right) activity of IN GSH and IN MF as compared to IN 1F. Data before normalization are plotted in Additional file 5: Figure S5. Data are plotted as mean \pm SD of 3 replicates. ${ }^{*}$ Denotes $P<0.05$, * denotes $P<0.01$, and ${ }^{* * *}$ denotes $P<0.0001$ 


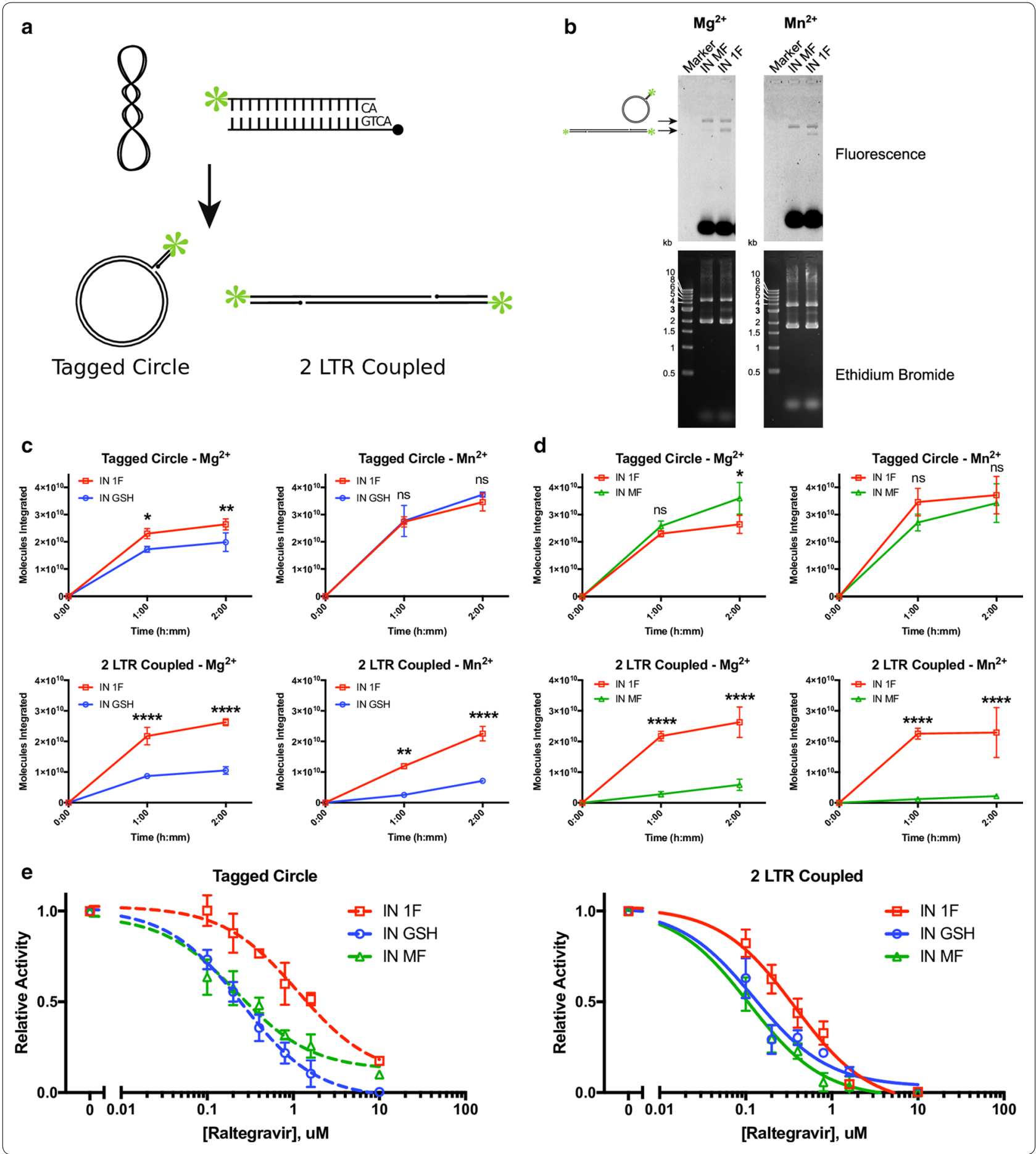


Fig. 4 ALLINI-induced aggregation of IN 1 F, IN GSH, and IN MF. a Aggregation of IN at $15 \mu \mathrm{M}$ was induced by incubation with $30 \mu \mathrm{M}$ of the ALLINIs BI-224436, BI-D, or CX04328 at a range of $\mathrm{NaCl}$ concentrations for $20 \mathrm{~min}$. Aggregation was measured by light scattering at $405 \mathrm{~nm}$. No aggregation was observed for any ALLINI at $1000 \mathrm{mM} \mathrm{NaCl}$. At intermediate $\mathrm{NaCl}$ concentrations, ALLINIs induce aggregation of IN $1 \mathrm{~F}$ more potently than IN GSH or IN MF. b Aggregation in the absence of ALLINIs. No aggregation was observed at $\mathrm{NaCl}$ concentrations of $300 \mathrm{mM}$ or greater. Below $300 \mathrm{mM}$, IN 1F, and, to a lesser extent, IN MF and IN GSH spontaneously aggregate. * Denotes $P<0.05$, ** denotes $P<0.01$, *** denotes $P<0.001$, **** denotes $P<0.0001$

The zinc finger fold of the NTD is shared with other DNA-binding proteins [92-94], with residues homologous to positions 1-3 in IN located adjacent to the phosphate backbone of DNA. In retroviral intasomes, the NTD binds to the distal viral DNA ends [19, 23-26, 39, 40]. However, unlike other helix-turn-helix binding proteins, the NTD does not insert a helix into the major groove of DNA, and F1 is distant from the phosphate backbone. The effect of the N-terminal disruption in IN GSH and IN MF is unclear, because the change is not expected to disrupt a tetrameric intasome. In the hexadecameric maedi-visna virus intasome, however, two pairs of NTDs are closely oriented head-to-head [25], forming a nearly identical NTD-NTD interface as that observed in the structure of IN $1 \mathrm{~F}$ and IN GSH NTD-CCD $_{\text {[66]. This }}$ hydrophobic dimerization interface would involve significant contributions from F1, in contrast to the dimerization interface of the isolated NTD which mainly involves the a3 helix [3]. Additional N-terminal residues, such as the N-terminal Sso7d-IN fusion, could induce a steric clash [24]. It is possible that such a disruption explains the presence of heterogeneous, poorly resolved higherorder intasomes reported in the cryo-EM studies of HIV-1 Sso7d-IN intasomes [23, 24]. Additionally, disruption of the a1 helix could affect binding to LEDGF, as the NTD cooperates with the CCD in binding LEDGF [13, 85]. Destabilization of the intasome and disruption of the IN-LEDGF interaction are possible explanations for the differences in concerted integration activity and STI sensitivity between IN 1F, IN GSH, and IN MF.

Surprisingly, we found IN $1 \mathrm{~F}$ to be more potently aggregated by ALLINIs compared to IN GSH and IN MF. ALLINIs cause the formation of open polymers of IN mediated by CCD-CTD interactions [61], and it is not immediately clear how addition of N-terminal residues affects this process. Previously, we have shown that the NTD is dispensable for ALLINI-induced aggregation [63], although others have reported that constructs lacking the NTD are resistant to ALLINI-induced aggregation [95], suggesting that the NTD plays a role in

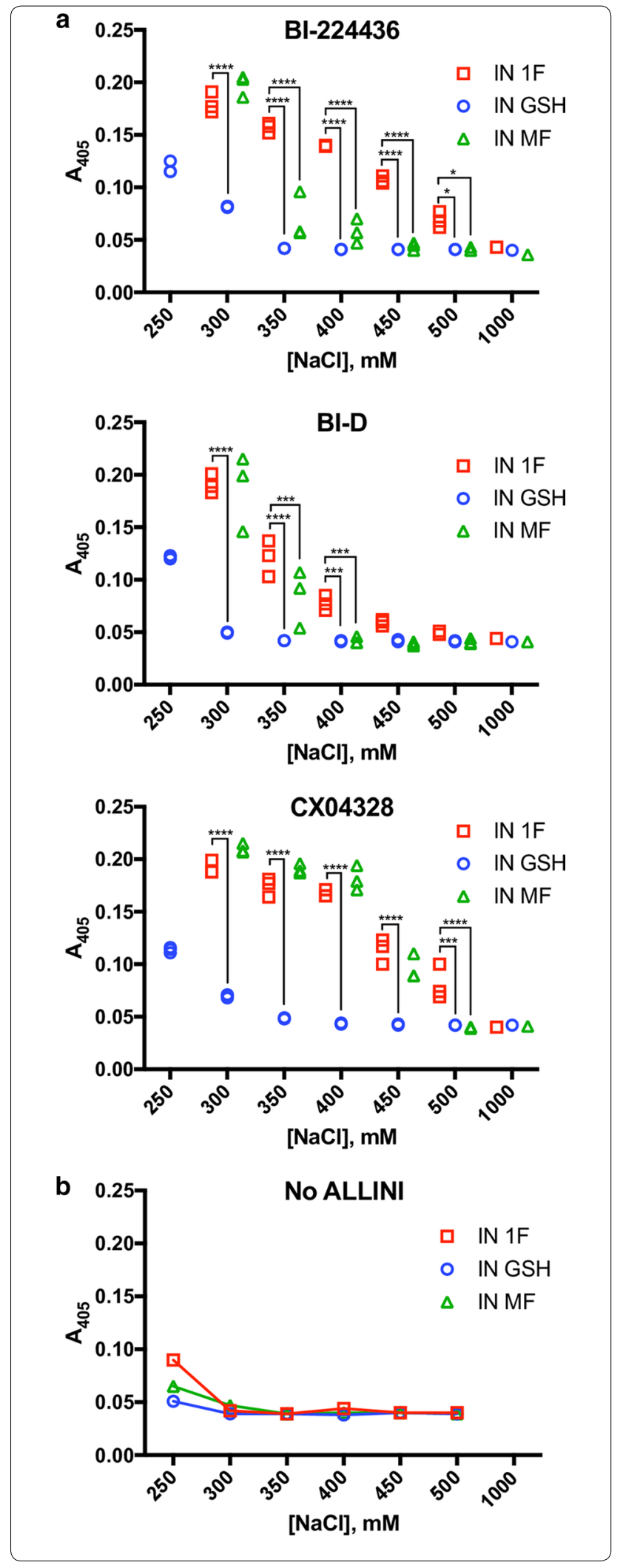



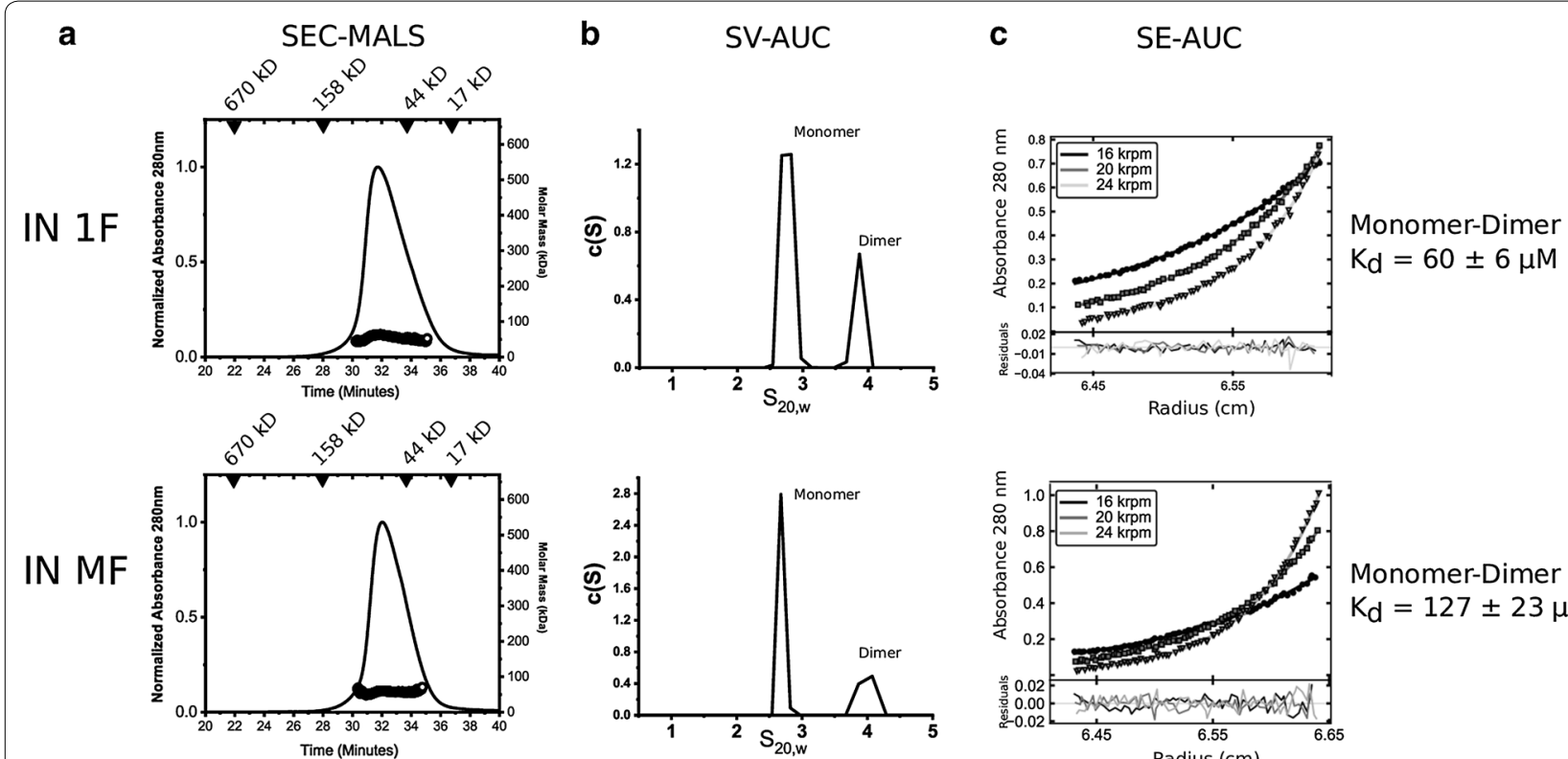

Fig. 5 Biophysical analysis of IN $1 F$ and IN MF. a SEC-MALS analysis of IN $1 F$ and IN MF. Both the $M_{w}$ (weight-average molecular mass) from multiangle light scattering and retention times are consistent with mixtures of monomers and dimers for both IN IF and IN MF (expected MW of monomer: $32 \mathrm{kDa}$ ). $\mathbf{b}$ Sedimentation velocity analysis of IN $1 \mathrm{~F}$ and IN MF shows distinct populations of monomer and dimer in solution. $\mathrm{C}(\mathrm{S})$ distributions derived from the fitting of the Lamm equation are shown. c Sedimentation equilibrium analysis of IN $1 F$ and IN MF indicates the presence of monomers and dimers in solution at $4{ }^{\circ} \mathrm{C}$. Globally fit radial distributions for $8.9 \mu \mathrm{M}$ (IN $1 \mathrm{~F}$ ) and $6 \mu \mathrm{M}$ (IN MF) in a monomer-dimer model are shown. Table 2 provides the association properties derived from this analysis

Table 2 Properties determined by sedimentation equilibrium analysis

\begin{tabular}{|c|c|c|c|c|c|c|}
\hline Protein & Concentrations $(\mu \mathrm{M})$ & Speeds (krpm) & Model fit & Mass $^{\mathrm{a}}(\mathrm{Da})$ & $\mathrm{K}_{\mathrm{d}}(\mu \mathrm{M})$ & $\begin{array}{l}\text { Global } \\
\text { reduced } \\
x^{2}\end{array}$ \\
\hline IN 1F & $8.9,14.5$ & $16,20,24$ & $M-D$ & 32,330 & $59.8 \pm 6$ & 2.7 \\
\hline IN MF & $6.0,7.9$ & $16,20,24$ & $M-D$ & 32,199 & $126.7 \pm 23$ & 1.3 \\
\hline
\end{tabular}

$M$ monomer, $D$ dimer

a Calculated mass of monomer from sequence

modulating ALLINI-induced aggregation. In multiple structures $[13,66,85]$, the NTD interacts with the CCD in a manner expected to clash with the CCD-CTD interactions observed in the ALLINI-induced IN polymer. An effect on competition between the NTD and CTD for CCD binding may explain the difference in ALLINI potency between IN 1F, IN GSH, and IN MF. Recently, IN tetramers have been implicated as the preferred target of ALLINIs [95], but we show that IN 1F, which is a mixture of monomers and dimers in solution, is aggregated by ALLINIs. However, aggregation is $\mathrm{NaCl}$-dependent, and we have not determined the oligomeric state of IN $1 \mathrm{~F}$ at lower $\mathrm{NaCl}$ concentrations. IN GSH remains soluble at $\mathrm{NaCl}$ concentrations that lead to aggregation of IN $1 \mathrm{~F}$ in the absence of ALLINI, demonstrating that additional
$\mathrm{N}$-terminal residues can improve solubility. This is consistent with the observation of improved solubility of Sso7d-IN [51] and PFV IN, which harbors an N-terminal extension domain [26, 41]. Additional experiments are needed to determine the details of ALLINI-induced polymer initiation and propagation.

Wild type IN $1 \mathrm{~F}$ is a mixture of monomers and dimers in solution, which differs from previously reported IN preparations containing substitutions at F185 or additional $\mathrm{N}$-terminal residues which are a mixture of dimers and tetramers $[13,43,61,64]$. We found that the substitution $\mathrm{F} 185 \mathrm{H}$ in the IN $1 \mathrm{~F}$ background resulted in the formation of higher-order species in solution. NTD-CCD interactions between residues such as E11 and K186 have been shown to be important for tetramerization $[13,95]$, 
and we have now shown that modification of the adjacent residue F185 affects oligomerization in the context of a native $\mathrm{N}$-terminus. Notably, the construct used to solve the only HIV IN crystal structure with a naturally-occurring F185, HIV-2 IN $_{\text {NTD-CCD }}$ co-expressed with LEDGF IBD, was dimeric in solution [85]. In this structure, the interdomain linker is clearly resolved in the electron density, showing that the NTD contacts the CCD in a "proximal" orientation. This is in contrast to the IN $\mathrm{GSH}_{\mathrm{NTD}-\mathrm{CCD}}$ structure (PDB: 1K6Y) where the interdomain linker is not resolved, short interdomain linkers are assigned, and each NTD is in a "distal" orientation [66]. The interdomain linker is not resolved in our $\mathrm{IN}_{1 \mathrm{~F}_{\mathrm{NTD}}}$ CCD structure, but we favor longer interdomain linkers, positioning each NTD in a "proximal" orientation, as this is the orientation observed in the HIV-2 IN $_{\text {NTD- }}$ CCD-LEDGF co-crystal structure [85]. Additional work is needed to understand the effect of substitutions at F185 and K186 on NTD-CCD interactions in dimeric forms of IN.

\section{Conclusions}

HIV IN containing a native $\mathrm{N}$-terminus adopts a distinct structural configuration, shows improved activity in vitro, and manifests altered sensitivity to inhibitors. Because it mimics the form of IN produced by proteolytic cleavage in the maturing virion, IN $1 \mathrm{~F}$ provides an improved reagent for the study of IN activity in vitro and for use in antiviral drug development.

\section{Supplementary information}

Supplementary information accompanies this paper at https://doi. org/10.1186/s12977-020-00537-x.

\begin{abstract}
Additional file 1: Figure S1. a) Purification scheme of IN with a native N-terminus (IN 1F). The poly-histidine (His7) affinity tag allows for capture of fusion proteins on $\mathrm{Ni}^{2+}-\mathrm{NTA}$ resin. Subsequent cleavage by the SUMO protease UIp1 frees wild type IN with a phenylalanine at position 1. b) Coomassie-stained SDS-PAGE analysis of IN constructs after Ulp1 cleavage and size-exclusion chromatography. Expected protein size is $32 \mathrm{kDa}$. c)

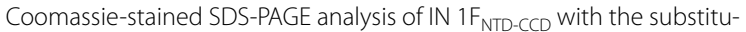
tions F185K, W131D, and F139D that enable crystallization. Expected protein size is $23 \mathrm{kDa}$.
\end{abstract}

Additional file 2: Figure S2. Models demonstrating two possibilities of NTD domain orientation. IN is depicted as a dimer with both NTDs in either the "distal" or "proximal" orientation. Models are based on PDB structures 1K6Y, 5HOT, and 6VRG.

Additional file 3: Figure S3. a) Secondary structure annotation of NTDs (residues 1-50) of IN 1F (PDB: 6VRG), IN GSH (PDB: 1K6Y), and Sso7d-IN (PDB: 5U1C, 6PUT, 6PUW, 6PUY, 6PUZ, and 6V3K) by DSSP. H = Alpha Helix, $\mathrm{G}=3_{10}$ Helix, $\mathrm{T}=$ Hydrogen bonded turn, and $\mathrm{S}=$ Bend. b) Comparison of Sso7d-IN a 1 helix structures. Chain A is predicted to form NTD-NTD interactions in dodecameric HIV-1 and hexadecameric MV intasomes. Chain B is not predicted to form NTD-NTD interactions.

Additional file 4: Figure S4. $\mathbf{N a C l}$-dependence of strand transfer activity. a) In the presence of $\mathrm{Mg}^{2+}$, IN $1 \mathrm{~F}$ and IN MF are most active at low $\mathrm{NaCl}$ concentrations, with activity disappearing above a $\mathrm{NaCl}$ concentration of $200 \mathrm{mM}$. The highest level of concerted integration activity is observed at
$150 \mathrm{mM} \mathrm{NaCl}$. b) In the presence of $\mathrm{Mn}^{2+}$, IN $1 \mathrm{~F}$ and IN MF are most active at $\mathrm{NaCl}$ concentrations higher than in the presence of $\mathrm{Mg}^{2+}$. The highest level of concerted integration activity is observed at $250 \mathrm{mM} \mathrm{NaCl}$.

Additional file 5: Figure S5. Effect of raltegravir on strand transfer activity of IN 1F, IN GSH, and IN 1F. Data are the same as in Fig. 3e but plotted as molecules integrated per minute of single strand (left) and concerted integration (right) without normalization. Data plotted as mean \pm SD of 3 replicates.

Additional file 6: Figure S6. Biophysical and biochemical characterization of IN $1 F^{\mathrm{F} 185 \mathrm{H}}$. a) SEC-MALS analysis of IN $1 \mathrm{~F}^{\mathrm{F} 185 \mathrm{H}}$ shows a mixture of dimers and higher-order aggregates in solution. b) Quantification of fluorescence polarization assay for $3^{\prime}$ processing. IN $1 \mathrm{~F}^{\mathrm{F} 185 \mathrm{H}}$ performs $3^{\prime}$-processing more rapidly than IN $1 \mathrm{~F}$, a difference that reaches statistical significance, but has unclear biological relevance. c) Example gel image of results from strand transfer assay in the presence of $\mathrm{Mg}^{2+}$. d) Quantification of strand transfer activity. The single strand and concerted strand transfer activity of $I N \mathrm{~F}^{\mathrm{F} 185 \mathrm{H}}$ is significantly decreased as compared to wild type IN 1F. Data plotted as mean \pm SD of 3 replicates. ${ }^{*}$ denotes $P<0.05$, ${ }^{* * *}$ denotes $P=0.0005,{ }^{* * *}$ denotes $P<0.0001$.

Additional file 7: File S7. Spreadsheet containing the underlying data for Figs. 2, 3, 4, Additional file 5: Figure S5, and Additional file 6: Figure S6.

\section{Abbreviations}

ART: Antiretroviral therapy; HIV: Human immunodeficiency virus; IN: Integrase; IN 1F: Integrase with native N-terminal phenylalanine; IN GSH: Integrase with Gly-Ser-His preceding N-terminal phenylalanine; IN MF: Integrase with methionine preceding N-terminal phenylalanine; NTD: N-terminal domain; CCD: Catalytic core domain; CTD: C-terminal domain; PFV: Prototype foamy virus; STI: Strand transfer inhibitor; RSV: Rous sarcoma virus; MMTV: Mouse mammary tumor virus; MVV: Maedi-visna virus; ALLINI: Allosteric integrase inhibitor; LEDGF: Lens epithelium-derived growth factor; IBD: Integrase binding domain; IPTG: Isopropyl- $\beta$-D-1-thiogalactopyranoside; CHAPS: 3-[(3-cholamidopropyl) dimethylammonio]-1-propanesulfonate; DTT: Dithiothreitol; AMX: Highly automated macromolecular crystallography; DIALS: Diffraction integration for advanced light sources; DSSP: Define secondary structure of proteins; NHS: N-hydroxysuccinimide; SV-AUC: Sedimentation velocity analytical ultracentrifugation; SE-AUC: Sedimentation equilibrium analytical ultracentrifugation; SAXS: Small angle X-ray scattering; LTR: Long terminal repeat; SEC-MALS: Sizeexclusion chromatography in line with multi-angle light scattering.

\section{Acknowledgements}

We thank Paul Bates, Robert Doms, Rahul Kohli, and Mitchell Lewis for suggestions and comments, and Laurie Zimmerman for help with the manuscript. This work was supported by the Penn Center for AIDS Research, the PennCHOP Microbiome Program, and the Johnson Research Foundation. SEC-MALS and AUC measurements were performed at the Johnson Research Structural Biology and Biophysics Core Facility. The crystallographic data were obtained at the 17-ID-1 (AMX) beamline at the National Synchrotron Light Source II, a U.S. Department of Energy (DOE) Office of Science User Facility operated for the DOE Office of Science by Brookhaven National Laboratory.

\section{Authors' contributions}

GE: conceptualization, formal analysis, investigation, methodology, visualization, writing-original draft preparation, writing-review and editing. KG: conceptualization, formal analysis, investigation, methodology, visualization, software, writing-original draft preparation, supervision, writing-review and editing, funding acquisition. AA: formal analysis, investigation, methodology, visualization. JZ, YH: investigation, methodology. MC: formal analysis, investigation, software. FDB: conceptualization, methodology, supervision, writingreview and editing, funding acquisition. GVD: conceptualization, investigation, methodology, supervision, writing-review and editing, funding acquisition. All authors read and approved the final manuscript.

\section{Funding}

FDB: U19-Al117950, UM1-Al126620 National Institute of Health, National Institute of Allergy and Infectious Diseases, www.niaid.nih.gov; R61-HL137063, R01-HL113252 National Institute of Health, National Heart, Lung, and Blood Institute, www.nhlbi.nih.gov. 
FDB, GVD: R01-Al129661 National Institute of Health, National Institute of Allergy and Infectious Diseases, www.niaid.nih.gov.

FDB, GE: T32-Al007632 National Institute of Health, National Institute of Allergy and Infectious Diseases, www.niaid.nih.gov.

FDB, KG: P30-Al045008 National Institute of Health, National Institute of Allergy and Infectious Diseases, www.niaid.nih.gov.

KG: R01-NS100081 National Institute of Health, National Institute of Neurological Disorders and Stroke, www.ninds.nih.gov.

Funding bodies had no role in the design of the study and collection, analysis, and interpretation of data and in writing the manuscript should be declared.

\section{Availability of data and materials}

All data generated and/or analysed during this study are included in this published article, its supplementary information files, and in the Worldwide Protein Data Bank repository under accession number 6VRG (Additional file 7).

\section{Ethics approval and consent to participate}

Not applicable.

\section{Consent for publication}

Not applicable.

\section{Competing interests}

The authors declare that they have no competing interests.

Received: 21 March 2020 Accepted: 21 August 2020

Published online: 31 August 2020

\section{References}

1. Craigie R, Bushman FD. HIV DNA integration. Cold Spring Harb Perspect Med. 2012;2(7):a006890.

2. Li X, Krishnan L, Cherepanov P, Engelman A. Structural biology of retroviral DNA integration. Virology. 2011;411(2):194-205.

3. Cai M, Zheng R, Caffrey M, Craigie R, Clore GM, Gronenborn AM. Solution structure of the $\mathrm{N}$-terminal zinc binding domain of HIV-1 integrase. Nat Struct Biol. 1997:4(7):567-77.

4. Zheng R, Jenkins TM, Craigie R. Zinc folds the N-terminal domain of HIV-1 integrase, promotes multimerization, and enhances catalytic activity. Proc Natl Acad Sci USA. 1996;93(24):13659-64.

5. Zhao Z, McKee CJ, Kessl JJ, Santos WL, Daigle JE, Engelman A, et al. Subunit-specific protein footprinting reveals significant structural rearrangements and a role for $\mathrm{N}$-terminal Lys-14 of HIV-1 Integrase during viral DNA binding. J Biol Chem. 2008;283(9):5632-41.

6. Engelman A, Craigie R. Identification of conserved amino acid residues critical for human immunodeficiency virus type 1 integrase function in vitro. J Virol. 1992;66(11):6361-9.

7. Kulkosky J, Jones KS, Katz RA, Mack JP, Skalka AM. Residues critical for retroviral integrative recombination in a region that is highly conserved among retroviral/retrotransposon integrases and bacterial insertion sequence transposases. Mol Cell Biol. 1992;12(5):2331-8.

8. Dyda F, Hickman AB, Jenkins TM, Engelman A, Craigie R, Davies DR. Crystal structure of the catalytic domain of HIV-1 integrase: similarity to other polynucleotidyl transferases. Science. 1994;266(5193):1981-6.

9. Chen JC-H, Krucinski J, Miercke LJW, Finer-Moore JS, Tang AH, Leavitt $A D$, et al. Crystal structure of the HIV-1 integrase catalytic core and C-terminal domains: a model for viral DNA binding. Proc Natl Acad Sci. 2000;97(15):8233-8.

10. Eijkelenboom APAM, Sprangers R, Hård K, Lutzke RAP, Plasterk RHA, Boelens $R$, et al. Refined solution structure of the c-terminal DNA-binding domain of human immunovirus-1 integrase. Proteins Struct Funct Bioinform. 1999;36(4):556-64.

11. Eijkelenboom APAM, Lutzke RAP, Boelens R, Plasterk RHA, Kaptein R, Hård K. The DNA-binding domain of HIV-1 integrase has an SH3-like fold. Nat Struct Biol. 1995;2(9):807-10.

12. Lodi PJ, Ernst JA, Kuszewski J, Hickman AB, Engelman A, Craigie R, et al. Solution structure of the DNA binding domain of HIV-1 integrase. Biochemistry. 1995;34(31):9826-33.
13. Hare S, Di Nunzio F, Labeja A, Wang J, Engelman A, Cherepanov P. Structural basis for functional tetramerization of lentiviral integrase. PLoS Pathog. 2009;5(7):e1000515.

14. Engelman A, Bushman FD, Craigie R. Identification of discrete functional domains of HIV-1 integrase and their organization within an active multimeric complex. EMBO J. 1993;12(8):3269-75.

15. Cherepanov P, Maertens G, Proost P, Devreese B, Van Beeumen J, Engelborghs $Y$, et al. HIV-1 integrase forms stable tetramers and associates with LEDGF/p75 protein in human cells. J Biol Chem. 2003;278(1):372-81.

16. Faure A, Calmels C, Desjobert C, Castroviejo M, Caumont-Sarcos A, Tarrago-Litvak L, et al. HIV-1 integrase crosslinked oligomers are active in vitro. Nucleic Acids Res. 2005;33(3):977-86.

17. McKee CJ, Kessl JJ, Shkriabai N, Dar MJ, Engelman A, Kvaratskhelia M. Dynamic modulation of HIV-1 integrase structure and function by cellular lens epithelium-derived growth factor (LEDGF) protein. J Biol Chem. 2008;283(46):31802-12.

18. Pandey KK, Bera S, Grandgenett DP. The HIV-1 integrase monomer induces a specific interaction with LTR DNA for concerted integration. Biochemistry. 2011;50(45):9788-96.

19. Engelman AN, Cherepanov P. Retroviral intasomes arising. Curr Opin Struct Biol. 2017:47:23-9.

20. Miller MD, Farnet CM, Bushman FD. Human immunodeficiency virus type 1 preintegration complexes: studies of organization and composition. J Virol. 1997;71(7):5382-90.

21. Lewinski MK, Bushman FD. Retroviral DNA integration - mechanism and consequences. In: Advances in genetics. Academic Press; 2005. p. 147-81.

22. Cook NJ, Li W, Berta D, Badaoui M, Ballandras-Colas A, Nans A, et al. Structural basis of second-generation HIV integrase inhibitor action and viral resistance. Science. 2020. https://doi.org/10.1126/science.aay4919.

23. Passos DO, Li M, Jóźwik IK, Zhao XZ, Santos-Martins D, Yang R, et al. Structural basis for strand transfer inhibitor binding to HIV intasomes. Science. 2020. https://doi.org/10.1126/science.aay8015.

24. Passos DO, Li M, Yang R, Rebensburg SV, Ghirlando R, Jeon Y, et al. CryoEM structures and atomic model of the HIV-1 strand transfer complex intasome. Science. 2017;355(6320):89-92.

25. Ballandras-Colas A, Maskell DP, Serrao E, Locke J, Swuec P, Jónsson SR, et al. A supramolecular assembly mediates lentiviral DNA integration. Science. 2017;355(6320):93-5.

26. Hare S, Gupta SS, Valkov E, Engelman A, Cherepanov P. Retroviral intasome assembly and inhibition of DNA strand transfer. Nature. 2010;464(7286):232-6.

27. Hare S, Maertens GN, Cherepanov P. 3'-Processing and strand transfer catalysed by retroviral integrase in crystallo. EMBO J. 2012;31(13):3020-8.

28. Maertens GN, Hare S, Cherepanov P. The mechanism of retroviral integration from $X$-ray structures of its key intermediates. Nature. 2010;468(7321):326-9.

29. Yin Z, Lapkouski M, Yang W, Craigie R. Assembly of prototype foamy virus strand transfer complexes on product DNA bypassing catalysis of integration. Protein Sci. 2012;21(12):1849-57.

30. Maskell DP, Renault L, Serrao E, Lesbats P, Matadeen R, Hare S, et al. Structural basis for retroviral integration into nucleosomes. Nature. 2015:523(7560):366-9.

31. Hazuda DJ, Felock P, Witmer M, Wolfe A, Stillmock K, Grobler JA, et al. Inhibitors of strand transfer that prevent integration and inhibit HIV-1 replication in cells. Science. 2000;287(5453):646-50.

32. Hazuda D. HIV integrase as a target for antiretroviral therapy. Curr Opin HIV AIDS. 2012;7(5):383-9.

33. Mesplède T, Wainberg MA. Integrase strand transfer inhibitors in HIV therapy. Infect Dis Ther. 2013;2(2):83-93.

34. You J, Wang H, Huang X, Qin Z, Deng Z, Luo J, et al. Therapyemergent drug resistance to integrase strand transfer inhibitors in HIV-1 patients: a subgroup meta-analysis of clinical trials. PLOS ONE. 2016;11(8):e0160087.

35. Mesplède T, Wainberg MA. Resistance against integrase strand transfer inhibitors and relevance to HIV persistence. Viruses. 2015;7(7):3703-18.

36. Johnson BC, Métifiot M, Ferris A, Pommier Y, Hughes SH. A homology model of HIV-1 integrase and analysis of mutations designed to test the model. J Mol Biol. 2013;425(12):2133-46. 
37. Krishnan L, Li X, Naraharisetty HL, Hare S, Cherepanov P, Engelman A. Structure-based modeling of the functional HIV-1 intasome and its inhibition. Proc Natl Acad Sci. 2010;107(36):15910-5.

38. Peletskaya E, Andrake M, Gustchina A, Merkel G, Alexandratos J, Zhou D, et al. Localization of ASV integrase-DNA contacts by site-directed crosslinking and their structural analysis. PLOS ONE. 2011;6(12):e27751.

39. Yin Z, Shi K, Banerjee S, Pandey KK, Bera S, Grandgenett DP, et al. Crystal structure of the Rous sarcoma virus intasome. Nature. 2016;530(7590):362-6.

40. Ballandras-Colas A, Brown M, Cook NJ, Dewdney TG, Demeler B, Cherepanov $\mathrm{P}$, et al. Cryo-EM reveals a novel octameric integrase structure for betaretroviral intasome function. Nature. 2016;530(7590):358-61 .

41. Gupta K, Curtis JE, Krueger S, Hwang Y, Cherepanov P, Bushman FD, et al. Solution conformations of prototype foamy virus integrase and its stable synaptic complex with U5 viral DNA. Structure. 2012;20(11):1918-28.

42. Hickman AB, Palmer I, Engelman A, Craigie R, Wingfield P. Biophysical and enzymatic properties of the catalytic domain of HIV-1 integrase. J Biol Chem. 1994;269(46):29279-87.

43. Jenkins TM, Engelman A, Ghirlando R, Craigie R. A soluble active mutant of HIV-1 Integrase involvement of both the core and carboxyl-terminal domains in multimerization. J Biol Chem. 1996;271(13):7712-8.

44. Sinha S, Grandgenett DP. Recombinant human immunodeficiency virus type 1 integrase exhibits a capacity for full-site integration in vitro that is comparable to that of purified preintegration complexes from virusinfected cells. J Virol. 2005;79(13):8208-16.

45. Sinha S, Pursley MH, Grandgenett DP. Efficient concerted integration by recombinant human immunodeficiency virus type 1 integrase without cellular or viral cofactors. J Virol. 2002;76(7):3105-13.

46. Craigie R, Fujiwara T, Bushman F. The IN protein of Moloney murine leukemia virus processes the viral DNA ends and accomplishes their integration in vitro. Cell. 1990;62(4):829-37.

47. Carteau S, Gorelick RJ, Bushman FD. Coupled integration of human immunodeficiency virus type 1 cDNA ends by purified integrase in vitro: stimulation by the viral nucleocapsid protein. J Virol. 1999;73(8):6670-9.

48. Bushman FD, Craigie R. Activities of human immunodeficiency virus (HIV) integration protein in vitro: specific cleavage and integration of HIV DNA. Proc Natl Acad Sci USA. 1991;88(4):1339-43.

49. Kalpana GV, Marmon S, Wang W, Crabtree GR, Goff SP. Binding and stimulation of HIV-1 integrase by a human homolog of yeast transcription factor SNF5. Science. 1994:266(5193):2002-6.

50. Goodarzi G, Im GJ, Brackmann K, Grandgenett D. Concerted integration of retrovirus-like DNA by human immunodeficiency virus type 1 integrase. J Virol. 1995;69(10):6090-7.

51. Li M, Jurado KA, Lin S, Engelman A, Craigie R. Engineered hyperactive integrase for concerted HIV-1 DNA integration. PLoS ONE. 2014;9(8):e105078.

52. Foley B, Leitner T, Apetrei C, Hahn B, Mizrachi I, Mullins J, et al. HIV sequence compendium 2018. 2018;448.

53. Lightfoote MM, Coligan JE, Folks TM, Fauci AS, Martin MA, Venkatesan S. Structural characterization of reverse transcriptase and endonuclease polypeptides of the acquired immunodeficiency syndrome retrovirus. J Virol. 1986;60(2):771-5.

54. Steimer KS, Higgins KW, Powers MA, Stephans JC, Gyenes A, GeorgeNascimento C, et al. Recombinant polypeptide from the endonuclease region of the acquired immune deficiency syndrome retrovirus polymerase (pol) gene detects serum antibodies in most infected individuals. J Virol. 1986;58(1):9-16

55. Lloyd AG, Ng YS, Muesing MA, Simon V, Mulder LCF. Characterization of HIV-1 integrase N-terminal mutant viruses. Virology. 2007;360(1):129-35.

56. Leavitt AD, Robles G, Alesandro N, Varmus HE. Human immunodeficiency virus type 1 integrase mutants retain in vitro integrase activity yet fail to integrate viral DNA efficiently during infection. J Virol. 1996;70(2):721-8.

57. Masuda T, Planelles V, Krogstad P, Chen IS. Genetic analysis of human immunodeficiency virus type 1 integrase and the U3 att site: unusual phenotype of mutants in the zinc finger-like domain. J Virol. 1995:69(11):6687-96.

58. Engelman A, Englund G, Orenstein JM, Martin MA, Craigie R. Multiple effects of mutations in human immunodeficiency virus type 1 integrase on viral replication. J Virol. 1995;69(5):2729-36.

59. Engelman A. In vivo analysis of retroviral integrase structure and function. Adv Virus Res. 1999:52:411-26.
60. Takahata T, Takeda E, Tobiume M, Tokunaga K, Yokoyama M, Huang Y-L, et al. Critical contribution of Tyr15 in the HIV-1 integrase (IN) in facilitating IN assembly and nonenzymatic function through the IN precursor form with reverse transcriptase. J Virol. 2016;91(1).

61. Gupta K, Turkki V, Sherrill-Mix S, Hwang Y, Eilers G, Taylor L, et al. Structural basis for inhibitor-induced aggregation of HIV integrase. PLoS Biol. 2016;14(12):e1002584.

62. Nomura Y, Masuda T, Kawai G. Structural analysis of a mutant of the HIV-1 integrase zinc finger domain that forms a single conformation. J Biochem. 2006;139(4):753-9.

63. Gupta K, Brady T, Dyer BM, Malani N, Hwang Y, Male F, et al. Allosteric inhibition of human immunodeficiency virus integrase: late block during viral replication and abnormal multimerization involving specific protein domains*. J Biol Chem. 2014;289(30):20477.

64. Gupta K, Diamond T, Hwang Y, Bushman F, Van Duyne GD. Structural properties of HIV integrase.lens epithelium-derived growth factor oligomers. J Biol Chem. 2010;285(26):20303-15.

65. Cai M, Huang Y, Caffrey M, Zheng R, Craigie $R$, Clore GM, et al. Solution structure of the His12-> Cys mutant of the N-terminal zinc binding domain of HIV-1 integrase complexed to cadmium. Protein Sci. 1998;7(12):2669-74

66. Wang J-Y, Ling H, Yang W, Craigie R. Structure of a two-domain fragment of HIV-1 integrase: implications for domain organization in the intact protein. EMBO J. 2001;20(24):7333-43.

67. Ciuffi A, Diamond TL, Hwang Y, Marshall HM, Bushman FD. Modulating target site selection during human immunodeficiency virus DNA integration in vitro with an engineered tethering factor. Hum Gene Ther. 2006;17(9):960-7

68. Diamond TL, Bushman FD. Division of labor within human immunodeficiency virus integrase complexes: determinants of catalysis and target DNA capture. J Virol. 2005:79(24):15376-87.

69. Diamond TL, Bushman FD. Role of metal ions in catalysis by HIV integrase analyzed using a quantitative PCR disintegration assay. Nucleic Acids Res. 2006;34(21):6116-25

70. Miller MS, Maheshwari S, Shi W, Gao Y, Chu N, Soares AS, et al. Getting the most out of your crystals: data collection at the new high-flux, microfocus MX Beamlines at NSLS-II. Molecules. 2019. https://doi.org/10.3390/molec ules24030496.

71. Fuchs MR, Bhogadi DK, Jakoncic J, Myers S, Sweet RM, Berman LE, et al. NSLS-II biomedical beamlines for micro-crystallography, FMX, and for highly automated crystallography, AMX: new opportunities for advanced data collection. AIP Conf Proc. 2016:1741(1):030006.

72. Winter G, Waterman DG, Parkhurst JM, Brewster AS, Gildea RJ, Gerstel M, et al. DIALS: implementation and evaluation of a new integration package. Acta Crystallogr Sect D Struct Biol. 2018;74(2):85-97.

73. Liebschner D, Afonine PV, Baker ML, Bunkóczi G, Chen VB, Croll TI, et al. Macromolecular structure determination using $X$-rays, neutrons and electrons: recent developments in Phenix. Acta Crystallogr Sect D Struct Biol. 2019;75(10):861-77.

74. Schrödinger LLC. The PyMOL molecular graphics system, Version 1.8. 2015.

75. Touw WG, Baakman C, Black J, te Beek TAH, Krieger E, Joosten RP, et al. A series of PDB-related databanks for everyday needs. Nucleic Acids Res. 2015;43(D1):D364-8.

76. Kabsch W, Sander C. Dictionary of protein secondary structure: pattern recognition of hydrogen-bonded and geometrical features. Biopolymers. 1983;22(12):2577-637.

77. Merkel G, Andrake MD, Ramcharan J, Skalka AM. Oligonucleotide-based assays for integrase activity. Methods. 2009;47(4):243-8.

78. Guiot E, Carayon K, Delelis O, Simon F, Tauc P, Zubin E, et al. Relationship between the oligomeric status of HIV-1 integrase on DNA and enzymatic activity. J Biol Chem. 2006;281(32):22707-19.

79. Gao K, Butler SL, Bushman F. Human immunodeficiency virus type 1 integrase: arrangement of protein domains in active cDNA complexes. EMBO J. 2001;20(13):3565-76.

80. Bushman FD, Fujiwara T, Craigie R. Retroviral DNA integration directed by HIV integration protein in vitro. Science. 1990;249(4976):1555-8.

81. Schuck P. Size-distribution analysis of macromolecules by sedimentation velocity ultracentrifugation and lamm equation modeling. Biophys J. 2000;78(3):1606-19. 
82. Hayes BD, Laue MT, Philo AJ. SEDNTERP (Sedimentation Utility Software). 2003. http://philo.rasmb.org/software/.

83. Vistica J, Dam J, Balbo A, Yikilmaz E, Mariuzza RA, Rouault TA, et al. Sedimentation equilibrium analysis of protein interactions with global implicit mass conservation constraints and systematic noise decomposition. Anal Biochem. 2004;326(2):234-56.

84. Mossessova E, Lima CD. Ulp1-SUMO crystal structure and genetic analysis reveal conserved interactions and a regulatory element essential for cell growth in yeast. Mol Cell. 2000;5(5):865-76.

85. Hare S, Shun M-C, Gupta SS, Valkov E, Engelman A, Cherepanov P. A novel co-crystal structure affords the design of gain-of-function lentiviral integrase mutants in the presence of modified PSIP1/LEDGF/p75. PLoS Pathog. 2009;5(1):e1000259.

86. Christ F, Voet A, Marchand A, Nicolet S, Desimmie BA, Marchand D, et al. Rational design of small-molecule inhibitors of the LEDGF/p75-integrase interaction and HIV replication. Nat Chem Biol. 2010;6(6):442-8.

87. Fader LD, Malenfant E, Parisien M, Carson R, Bilodeau F, Landry S, et al. Discovery of BI 224436, a noncatalytic site integrase inhibitor (NCINI) of HIV-1. ACS Med Chem Lett. 2014;5(4):422-7.

88. Wang H, Jurado KA, Wu X, Shun M-C, Li X, Ferris AL, et al. HRP2 determines the efficiency and specificity of HIV-1 integration in LEDGF/ p75 knockout cells but does not contribute to the antiviral activity of a potent LEDGF/p75-binding site integrase inhibitor. Nucleic Acids Res. 2012:40(22):11518-30.

89. Jurado KA, Wang H, Slaughter A, Feng L, KessI JJ, Koh Y, et al. Allosteric integrase inhibitor potency is determined through the inhibition of HIV-1 particle maturation. Proc Natl Acad Sci USA. 2013;110(21):8690-5.
90. Tsantrizos Y, Bailey M, Bilodeau F, Carson R, Coulombe R, Fader L, et al. Inhibitors of human immunodeficiency virus replication. World Patent. /2009/062285. 2009. https://patentscope.wipo.int/search/en/detai l.jsf?docld=WO2009062285.

91. Engelman A, Liu Y, Chen H, Farzan M, Dyda F. Structure-based mutagenesis of the catalytic domain of human immunodeficiency virus type 1 integrase. J Virol. 1997;71(5):3507-14.

92. Otwinowski Z, Schevitz RW, Zhang R-G, Lawson CL, Joachimiak A, Marmorstein $\mathrm{RQ}$, et al. Crystal structure of trp represser/operator complex at atomic resolution. Nature. 1988;335(6188):321-9.

93. van Pouderoyen G, Ketting RF, Perrakis A, Plasterk RHA, Sixma TK. Crystal structure of the specific DNA-binding domain of TC3 transposase of $C$. elegans in complex with transposon DNA. EMBO J. 1997;16(19):6044-54.

94. Xu W, Rould MA, Jun S, Desplan C, Pabo CO. Crystal structure of a paired domain-DNA complex at $2.5 \mathrm{~A}$ resolution reveals structural basis for Pax developmental mutations. Cell. 1995;80(4):639-50.

95. Koneru PC, Francis AC, Deng N, Rebensburg SV, Hoyte AC, Lindenberger J, et al. HIV-1 integrase tetramers are the antiviral target of pyridine-based allosteric integrase inhibitors. Elife. 2019;8:e46344.

\section{Publisher's Note}

Springer Nature remains neutral with regard to jurisdictional claims in published maps and institutional affiliations.
Ready to submit your research? Choose BMC and benefit from:

- fast, convenient online submission

- thorough peer review by experienced researchers in your field

- rapid publication on acceptance

- support for research data, including large and complex data types

- gold Open Access which fosters wider collaboration and increased citations

- maximum visibility for your research: over 100M website views per year

At BMC, research is always in progress.

Learn more biomedcentral.com/submissions 